\title{
Back Analysis of Short-Term Seismic Hazard Indicators of Larger Seismic Events in Deep Underground Mines (LKAB, Kiirunavaara Mine, Sweden)
}

\author{
Emilia Nordström, ${ }^{1}$ SAvka Dineva, ${ }^{1}$ and Erling Nordlund ${ }^{1}$
}

\begin{abstract}
Back analysis for evaluation of the merits of the short-term seismic hazard indicators (precursors) used in the mines and their potential application for early warning was carried out for fourteen seismic events that potentially caused damage in Kiirunavaara Mine, Sweden, selected according to our designed criteria. Five short-term hazard indicators: Seismic Activity Rate (SAR), Cumulative Seismic Moment (CSM), Energy Index (EI), Cumulative Apparent Volume (CAV) and Seismic Apparent Stress Frequency (ASF) were tested. The behaviour of the indicators was studied using the parameters of all seismic events within a sphere around the hypocenter location of the analyzed seismic source within one month before the main (damaging) event. The size of the sphere equals the estimated radius of the analyzed seismic source (area of inelastic deformation). mXrap software (Australian Centre for Geomechanics) was used for data visualization, manipulation, analysis and extraction. The results from the main analysis showed a good agreement between the expected and actual behaviour of the SAR, CSM and CAV indicators. In overall, CSM and CAV ranked the highest positive/expected behaviour followed by SAR (Table 3). The EI and ASF ranked lowest and showed to be sensitive to the number of events within the source sphere. The rate of false warnings and missed warnings was also investigated for the 25 days-long period before the damaging events. A similar trend was observed as for the main analysed event. The results from this study can be used for further improvement of the short-term hazard estimations and early warning system in deep underground mines.
\end{abstract}

Keywords: Induced seismicity in mines, seismic hazards, rockbursts, mine seismology.

\section{Introduction}

The current study is a continuation of a previous work, which focused on seismic event source parameter evaluation for the same block at Kiirunavaara mine (Nordström et al. 2017). The next on-

1 Division of Mining and Geotechnical Engineering, Luleå University of Technology, 97187 Luleå, Sweden. E-mail: emilia. nordstrom@1tu.se; savka.dineva@1tu.se; erling.nordlund@1tu.se going work is on rock damage due to seismic dynamic loading (detailed study of the characteristics of the damage) and its correlation with the local geological structures, rock mechanical parameters, local stresses, and source parameters. The final goal of the series of these studies is to obtain more information required for improved forecast of seismic/damage hazard in Kiirunavaara Mine.

Kiirunavaara mine is one of the most modern large sublevel caving iron ore mine located in a north-most small town of Kiruna. About 28 million tonnes of iron ore are produced per annum. Fragmentation of the ore is done by large production blasts (Wimmer and Nordqvist 2018). The iron orebody that is estimated to be about $5 \mathrm{~km}$ long and $80 \mathrm{~m}$ wide strikes nearly North-South and dips $50^{\circ}-$ $70^{\circ}$ towards east. It consists mainly of magnetite that lies between syenite porphyries and quartz bearing porphyries. The footwall and hanging wall have different geology. The footwall consist of Precambrian aged tracho-andesites referred to as syenite porphyries and the hanging wall consist of quartz (rhyolite) porphyry.

The mine has the largest underground seismic system in the world with 204 operational sensors (geophones) by 2016. It was declared seismically active after 2007-2008. In the recent years the seismic system records many thousands of events every day. The magnitude threshold of recorded events changed with time. The most recent one is around - 1.4 (Dineva and Boskovic 2017). The seismic source parameters are calculated manually by the Institute of Mine Seismology (IMS) following the methodology described in Nordström et al. (2017). The average hypocentre location error is the order of $23 \mathrm{~m}$ (du Toit 2015). 
Given the increasing production depth in Kiruna mine (> 700-800 $\mathrm{m}$ ) and the corresponding seismic hazard that poses threat on the production and mine personnel, a need for a study of the merits and reliability of the short-term seismic hazard assessment parameters that are currently used in the mines was identified. Time-dependant forecast models divided into short-, medium- and long-term have been developed to provide the likelihood of an event occurring or to indicate areas of high seismic hazard. Different stress and deformation hazard indicators have been defined by different authors in several studies. It should be stressed that there are no consistently reliable methods of short-term seismic hazard assessment in mines. The real progress of seismic hazard assessment in mines is not very large nor as widely developed as compared to tectonic earthquakes. Some of the hazard indicators were tested in some mines; however, their combined performance success rate was not quantified. More testing of these different approaches need to be done to evaluate the success rate and performance of different indicators.

Therefore, this study aims firstly at acquiring a comprehensive summary of different approaches and parameters currently used in mines for seismic hazard assessment derived from mining-induced and natural seismicity; and secondly, evaluation of the performance merits of some selected promising parameters used to assess the short-term hazard in underground mines. Fourteen larger seismic events $\left(>0.9 \mathrm{M}_{\mathrm{w}}\right)$ were selected out of previously studied 46 seismic damaging events (Nordström et al. 2017) for shortterm seismic hazard back analysis in this study. The performance, merits and reliability of these hazard indicators (parameters) currently used in the mines: Seismic Activity Rate (SAR), Cumulative Seismic Moment (CSM), Energy Index (EI), Cumulative Apparent Volume (CAV) and Seismic Apparent Stress Frequency (ASF) were evaluated and their potential for seismic hazard warning was determined. Therefore, this overall study aims at evaluating the potential for using these indicators in a systematic way in the future and defining the potential future development in automatic mine-wide forecast. The present study is based on a manual evaluation of their performance.

\section{Theoretical Background}

"Seismic event prediction" is expected to provide time, location and magnitude of the future seismic event. To date, this is impossible, in general for natural earthquakes and in particular for seismic events in mines. Instead, a "seismic hazard forecast" approach is adopted where time- dependant forecast models are developed to provide the likelihood of an event occurring or to indicate areas of high seismic hazard (Spottiswode 2009). Here we consider only forecast based on seismic source parameters and derived parameters from them.

The forecast could be a formal rule or rules for the behavior (pattern) of certain parameters before the seismic events based on multifold observations in the past behavior. Similar approach was proposed by Keilis-Borok et al. (2002) and used for example for forecast of volcanic eruptions based on daily seismicity rate (e.g. Grasso and Zaliapin 2004). In other cases numerous parameters were used in a combination e.g. number of main shocks, the deviation from the long-term trend, cumulative number of main shocks, linear concentration of the main shocks etc. (e.g. Kossobokov et al. 1999). More sophisticated advanced approach was developed and used by Shebalin et al. (2004, 2006). In this case short-term spatial and temporal patterns were used as precursors for short-term earthquake forecast, combined in socalled precursory chains to identify the place and time of a future earthquakes. Different seismicity indicators (attributes based on the b-value from the Gutenberg-Richter law) were used with supervised learning to predict large earthquakes (Asencio-Cortes et al. 2016). Other machine learning regressors were also used with cloud-based big data infrastructure (Asencio-Cortés et al. 2018). Summary of the seismicity-based forecast techniques is available in Tiampo and Shcherbakov (2012). They divided the techniques (models) into (1) physical process models including parameters as accelerating moment release, variation in b-value etc.; seismicity changed prior to large events-as RTL-the distance-time-rupture length of clustered seismicity or PI-pattern informatics; or seismic energy changes (Load-Unload Response Ratio); and (2) smoothed seismicity models with important physical spatio-temporal features of 
earthquake processes, that characterize these features in a mathematical and/or probabilistic manner (e.g. EEPAS - every earthquake as a precursor, time-independent smoothed seismicity, ETAS-epidemictype aftershock sequence, RI-relative intensity, Non-Poissonian earthquake clustering, STEP-shortterm earthquake probability for aftershock sequences, HAZGRIDX based on smoothing governed by Guternberg-Richter relation etc.).

Our approach is comparatively simple. It is using a few indicators derived from the seismic source parameters and their behaviour (patterns) before large seismic events, similar to the approach used by Grasso and Zaliapin (2004). It can be related to the physical process models. The parameters that we used are routinely calculated in underground mines. Some of them usually are not calculated for natural tectonic earthquakes (e.g. apparent volume, energy index).

\subsection{Methods of Seismic Hazard Assessment in Mines}

The hazard forecast models are classified into three time periods, related to the nature of mining: short- (up to 3 days), medium- (3-30 days) and long-term (1-12 months). The parameters mostly used for these time periods are based on quantitative seismological parameters found in a series of publications by Mendecki (1993, 1997a, b); van Aswegen and Rebuli (1993), and van Aswegen (2005). Initially, these time periods were used for South-African mines but gradually they were adopted in some other mines worldwide.

Long-term seismic hazard assessment is crucial for mine planning. It adopted two main approaches from natural earthquakes: Deterministic Seismic Hazard Assessment (DSHA) and Probabilistic Seismic Hazard Assessment (PSHA). A combination of these approaches is also used. DSHA involves numerical modelling to obtain ERR (Energy Release Rate), ESS (Excess Shear Stress), VER (Volumetric Energy Release) and Average Pillar Stress (APS) of the rock mass. Known seismic sources are used to verify and calibrate the models. Detailed description of these parameters and their relations to seismic hazard is found in Jager and Ryder (2001), Lachenicht (2001), Wiles (1998). PHSA uses a classical Gutenberg-Richter frequency-magnitude relation to forecast the largest expected event magnitude. The main two parameters derived from a GutenbergRichter frequency-magnitude relations are the rate of the events of a given magnitude (seismic activity) and the b-value (the slope of the line). These parameters are used to determine the probability of occurrence of seismic events above a certain magnitude and the maximum possible magnitude $M_{\max }$ (e.g. Kijko and Funk 1994) and they are time-dependent as well as they change as a function of the mining environment and production.

Medium-term seismic hazard assessment is done on monthly basis and involves identification of areas that are prone to large events. The parameters mostly used for medium-term hazard are derived from seismological parameters and are related-to-mining parameters such as inelastic strains and stress, e.g. Energy Index (EI), apparent stress, unstable rock mass behavior and hazard magnitude determined for each identified region (van Aswegen 2005). In addition, some parameters from numerical modelling can also be used in medium-term hazard assessment to identify regions of unstable rockmass. The forecast models consider that the mining environment does not change significantly over monthly time periods. The forecast is made for seismic regions of interest defined by event clusters associated with mining layout and known geological structures. However, for recognition of unstable structures, geological dykes or faults and other unstable zones the development of the associated spatial seismic event clusters is interpreted for all seismic hazard assessment periods (short-, medium-, and long-term).

Short-term hazard assessment is performed on daily basis to indicate any spatial and temporal hazard variations, and possible areas of rock instabilities where a large seismic event is likely to occur in the next few hours or days (van Aswegen 2005). Several quantitative seismological parameters are used to monitor temporal patterns of stress variations and seismic deformation, which indicate areas of rock mass deformation and instabilities.

\subsection{Selection of Short-Term Hazard Parameters and Indicators}

In order to be able to monitor rock mass response to mining, one must be able to quantify continuously 
in time and space the parameters that describe the seismic flow-a seismic component of inelastic deformation that adjust rock towards local equilibrium, reducing and transferring stresses. From a seismological point of view the portion of the released stress and strain associated with the seismic sources can be measured and the rheology of the rock mass can be quantified (Mendecki 1997a, b).

Even though a number of parameters have been defined to be indicators of increased seismic hazard in the mines, after a critical review of all parameters for the purpose of this study, we have identified and used five short-term hazard parameters (indicators): Activity Rate (SAR), Cumulative Seismic Moment (CSM), Energy Index (EI), Cumulative Apparent Volume (CAV) and Seismic Apparent Stress Frequency (ASF), as they are the most commonly used parameters for estimating seismic hazard and are also incorporated in the current seismic database in LKAB mine. These parameters, summarized in Table 1, are derived parameters from seismic radiated energy, seismic moment, and number of events. The routine analyses and variations of these parameters are based on temporal patterns that reflect the physical processes and indicate areas of rockmass instabilities (Rebuli and van Aswegen 2013).

Full review of the definitions of these parameters can be found in a number of publications (e.g. Mendecki 1993, 1997a, b; Hudyma 2008; Kijko 1997; Gibowicz and Kijko 1994; van Aswegen 2003a, b, 2005; van Aswegen and Butler 1993; Hoffmann et al. 2001; Spottiswode 2004a, b).
Seismic activity rate (SAR) measures the number of seismic events per unit time over a specific moving time span $\Delta t$, usually 3 days. High rate of SAR indicates instability in rockmass condition, hence increased seismic hazard (Mendecki and van Aswegen 2001).

Cumulative apparent volume $\left(\mathrm{CAV}, \mathrm{V}_{\mathrm{A}}\right)$ is derived from the scalar seismic moment, $\mathrm{M}_{0}$ and the apparent stress $\sigma_{\mathrm{A}} . \mathrm{V}_{\mathrm{A}}$ is a scalar which measures the volume of rock with co-seismic inelastic strain with accuracy in the order of the magnitude of the apparent stress, divided by $\mu$ (shear modulus). CAV is believed to be stable and not model dependent parameter as it scales with $\sigma_{\mathrm{A}}$ (Mendecki and van Aswegen 2001). It is used to measure an increase in the rate of co-seismic deformation due to the increase in SAR or the softer nature of the events occurring within the already fractured zone. High CAV indicates acceleration in deformation. CAV can also be used to measure the ratio of seismic response to production against time to detect whether seismicity lags behind or runs ahead. This is because the volume of rock removed from depths is the driving force of the mine seismicity and it is quantifiable.

The cumulative seismic moment (CSM) shows the rate of co-seismic deformation. A possible increase in CSM would indicate high likelihood of a large event to occur (Mendecki and van Aswegen 2001).

Apparent stress frequency (ASF) is defined as the daily number of events with apparent stress equal or greater than a threshold, in a trailing (preceding) time

Table 1

Definition of the parameters (indicators) for short-term hazard assessment

\begin{tabular}{lll}
\hline Parameter/reference & Indicator & Definition \\
\hline $\begin{array}{l}\text { Seismic activity rate (SAR) (Mendecki and van Aswegen } \\
\text { 2001) }\end{array}$ & Hazard/unstable rockmass & $=$ number of events $/$ time \\
$\begin{array}{l}\text { Cumulative apparent volume (CAV) (Mendecki } \\
\text { and van Aswegen 2001) }\end{array}$ & Coseismic inelastic deformation/shear stress & $\sum V_{A}=\frac{M_{0}}{2 \sigma_{A}}=\frac{M_{0}^{2}}{2 \mu E}$ \\
$\begin{array}{l}\text { Cumulative seismic moment (CSM) (Mendecki } \\
\text { and van Aswegen 2001) }\end{array}$ & Deformation/strain & $\sum M_{0}=\mu \in_{p} V=\Delta \sigma V \geq \frac{M_{0}}{\Delta \sigma}$ \\
$\begin{array}{l}\text { Apparent stress frequency (ASF) (Hudyma 2008) } \\
\text { Energy Index (EI) (van Aswegen and Butler 1993) }\end{array}$ & Significant stress and seismic hazard & $=$ Average daily frequency of \\
apparent stress
\end{tabular}

$E I$ energy index, $E$ radiated seismic energy, $\bar{E}$ average radiated seismic energy, $M_{O}$ seismic moment, $V$ volume, $V_{A}$ apparent volume, $\mu$ rigidity, $\epsilon_{p}$ plastic strain, $\sigma_{A}$ apparent stress. and $\sigma$ stress drop 
period (Hudyma 2008). The apparent stress $\left(\sigma_{\mathrm{A}}\right)$ is an important measure which does not require specific assumptions for the source model and only depends on the ratio between the seismic moment and seismic energy. It expresses the amount of radiated seismic energy per unit volume of inelastic co-seismic deformation (Aki 1966; Wyss and Brune 1968). High or low apparent stress of seismic events of similar moments indicates high or low stress level and rock strength. Big variations in apparent stress therefore indicate inhomogeneity in stress and rock strength. A source with weak geological feature or soft patch in the rockmass is expected to yield slowly under lower differential stress producing larger seismic moment and radiating less seismic energy whereas a strong geological feature or hard patch will have an opposite behaviour (Mendecki 1993).

ASF follows the variations of apparent stress using time history chart called Apparent Stress Time History (ASTH). It is used as a good indicator of elevated temporal seismic hazard and is considered to be a reliable seismic hazard indicator when the seismic source mechanism strongly relates to volumetric stress change. According to Hudyma, a threshold value of 10 to $30 \mathrm{kPa}$ is considered a good value and it is usually identifying the top $10-20 \%$ of high apparent stress events. A trailing time period of 3-7 days is considered to produce a good trend. The ASF is expected to increase before larger seismic event occurs and to drop after due to stress redistribution. Examples of ASF threshold variations associated with likelihood of a large event to occur are addressed in Hudyma (2008). In this study the least possible threshold values $(10 \mathrm{kPa})$ were used based on the recorded apparent stress values of the analysed data with a trailing time period of 1 day.

The Energy Inde (EI) is the ratio of the observed radiated seismic energy $E$ of an event to the average radiated energy by an event with the same seismic moment $\bar{E}\left(M_{0}\right)$ taken from $\log$ (Energy) versus $\log$ (Moment) relation for the volume of interest. In other words, it shows the relative amount of energy released for a seismic event compared to the average expected amount of energy for that events seismic moment. EI independently measures the stress acting at the source of a seismic event. EI $>1$ indicates more energy is released for the seismic event than expected and shows stress increase in the rockmass. $\mathrm{EI}<1$ indicates less energy released for the seismic event than expected and shows that the rockmass may be distressing/relaxing or yielding. EI is expected to decrease in unstable rockmass conditions before a large event occurs and to drop suddenly after the event has taken place due to relaxation within the rockmass (van Aswegen 2013).

As shown in Table 1, there is a dependency between the selected indicators. Three indicators (CAV, CSM, and EI) provide information about the rate and distribution of coseismic deformation and/or stress changes in the rockmass but depend on the seismic moment in a very different way and. Both the CAV and CSM are indicators of deformation but CAV depends also on the apparent stress while CSM depends on the stress drop. As the apparent stress and the stress drop are calculated independently and are not always strictly proportional some redundancy in the deformation indicators can provide assurance that changes in the deformation can be captured by either one of the indicators. On the other hand, ASF also depends on the apparent stress but this indicator shows only stress changes. Theoretically, SAR and CSM are not independent but even when b-value is constant; they could show slightly different trends because the local magnitude here is calculated as function of the energy and seismic moment not only the seismic moment. CAV and EI works well together where CAV is expected to increase and EI to drop due to relaxation within the rock mass before a large seismic event takes place.

Rebuli and van Aswegen (2013) summarized the procedures for short-term hazard in South African group. They used routinely seismic indicators as seismic activity, apparent volume (Mendecki 1993) and energy index (van Aswegen and Butler 1993) and later on Schmidt number (Mendecki 1997a, b). Spatial clustering of the events was also taken into account. Back analysis was carried on to determine statistically the success rate of different parameters for four mines in four years (2005-2009) on a daily basis using manual ratings. The results showed that the success depended to high degree on the areal coverage by seismic sensors and where seismic activity rate was low with the occasional large event along a geological structure, rating system used was 
not successful. The authors concluded that the manual rating showed reasonable success rate but they did not rate different parameters.

Hudyma (2008) tested ASF in different mines in Australia and found that different thresholds levels works for different mines.

\section{Back Analysis of Short-Term Seismic Hazard Parameters (Indicators)}

The behaviour of all five parameters described above (SAR, CSM, EI, CAV and ASF) for 14 seismic damaging events recorded at Kiirunavaara mine were back analysed and their performance merits towards short-term seismic hazard were evaluated. The SAR, CSM, CAV and ASF indicators are expected to increase and EI is expected to drop before a seismic event occurred. The agreement of the behavior of these parameters with the expected or forecasted performance was studied. The similarities and differences in the temporal behavior of the parameters for all studied events were analyzed. Additionally, the behavior of the parameters was studied to obtain information about "false warnings" (expected behavior but no seismic event occurred) and "no warnings" (seismic event occurred but not indicator expected behavior or warning) indications for the 25 days-period (background seismicity) before the main analyzed events (30-5 days before the main event). The behavior of the main analysed event is the main core of the current study. Initially a 3-day period before the main analysed event was considered as it is normally done in short-term hazard analysis. However, during the preliminary analysis was found that the behavior of the parameter could be underestimated and hence, considered a different time interval (5-day period). Detailed reason why a 5-day period was chosen is discussed in details under the results in Sect. 3.3. The 25-day period was complimentary to the current study and was used to study the background behavior of the indicators and to see if similar patterns of behaviour that were expected for the main events could be found in the background seismicity (25-day period).

\subsection{Criteria for Selection of Seismic Damaging Events for Back Analysis}

Criteria were developed (Table 2) during the study to select suitable seismic events out of 46 already studied seismic events having occurred in block 33/34 of the LKAB Kiirunavaara Mine between 2008 and 2013 (Nordström et al. 2017) for further back analysis to evaluate the performance merits of the short-term seismic hazard parameters (indicators) used in mines and their potential application for early warning.

To be able to apply the criteria on all analyzed events with $M_{L}$ range between -1.8 and $2.0\left(\mathrm{M}_{\mathrm{w}}\right.$ range between -1.3 and 2.1 ), we firstly considered and classified any events with $M_{L} \geq 0.8$ as a large and $M_{L}<0.8$ as small. The event selection criteria outcome is summarized in Table 2. Fourteen seismic events were selected following the developed criteria and back analyzed. The local magnitude range of the selected seismic events is between 0.8 and 2.0 and moment magnitude is between 0.9 and 2.1. These seismic events were identified as the events that caused damage (rock fall, rock bursts) based on the time and location proximity. At this moment there is no confirmed proof about the relationship and that is why we consider that only potentially these seismic events caused the damage. Out of the total selected events one was far from the production areas, and the other had a series of aftershocks. It is believed that the preparation of the event far from the production would have minimal effect from mining activities and this would probably provide more insights of the main driving factors causing the seismic events. The

Table 2

Criteria used to select events for short-term hazard back analysis and the corresponding number of events that fit the criteria

Event description criteria Event moment magnitude $\left(M_{L} \geq 0.8\right)$ criteria

1. Damaging large events $\left(M_{L}\right)$ in or 11 close to the production area

2. Damaging events with aftershock 2 series in or close to the production area

3. Damaging events far from the 1 production area 


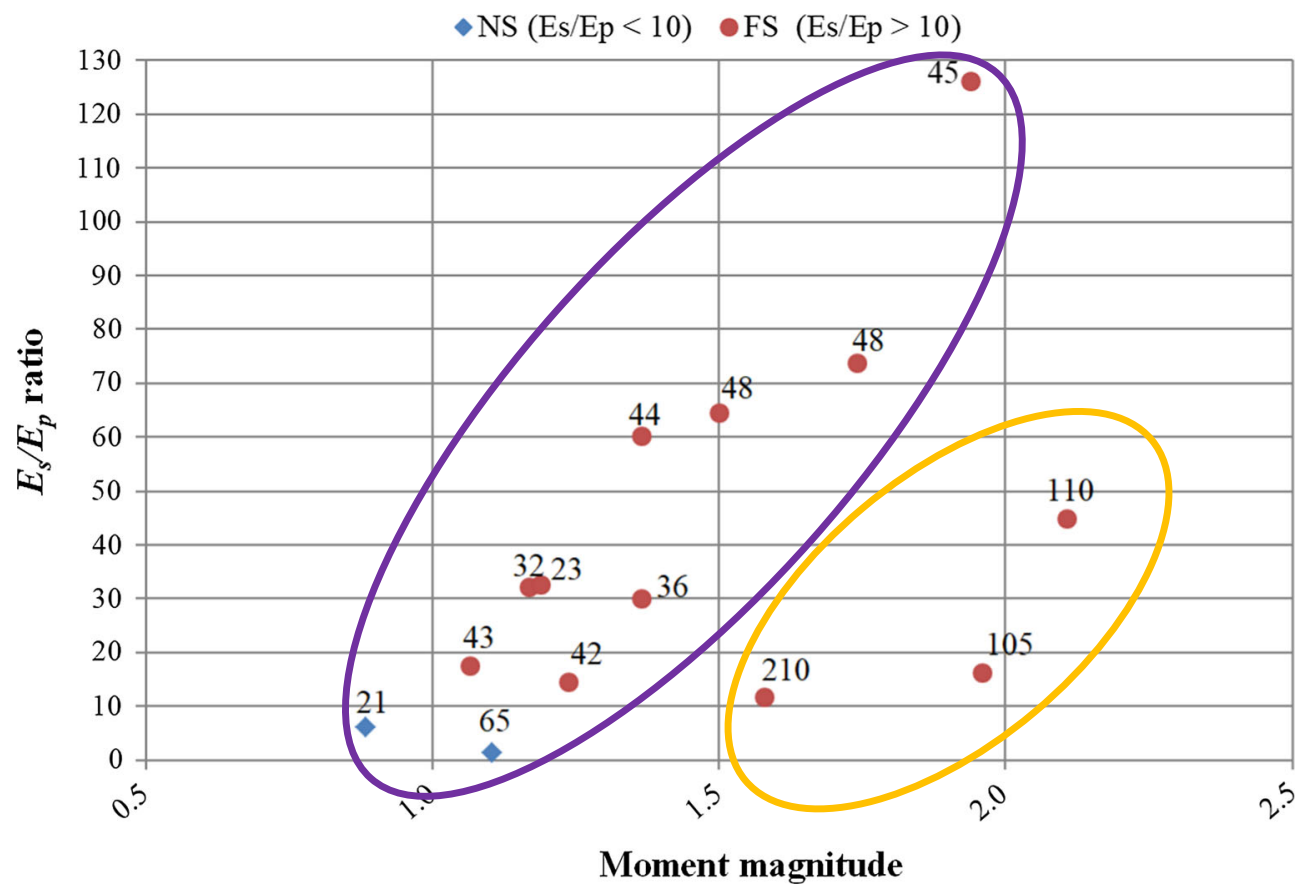

Figure 1

The $E_{S} / E_{P}$ ratio versus the moment magnitude for the selected events for back analysis. The labels are the source radius (Brune et al. 1979) of the events in meters. The events were separated into NS (Non-Shear, blue) and FS (Fault Slip, red) depending on the $E_{S} / E_{P}$ ratio (see the legend)

$E_{S} / E_{P}$ ratio (proxy of the source mechanism) of the selected seismic events with respect to $M_{w}$ is presented in Fig. 1.

The selected events have source radius from 19 to $210 \mathrm{~m}$, calculated by the formula from Brune et al. (1979). Out of 14 selected seismic events, 12 events had a fault slip (FS) source mechanism $\left(E_{S} / E_{P}\right.$ from 11 to 126) with a moment magnitude ranging between 1.1 and 2.1, and source radius between 19 and $210 \mathrm{~m}$; the other 2 events had non-shear (NS) source mechanism $\left(E_{S} / E_{P}<10\right)$ with a moment magnitude of 0.9 and 1.1 and source radius of 21 and $65 \mathrm{~m}$ (Fig. 1). The FS events had larger moment magnitudes compared to the NS events. The selected events formed two groups: one with events with source radius up to $68 \mathrm{~m}$ (purple circle) and the second group had three events with larger source radii from 105 to $210 \mathrm{~m}$ (yellow circle). It is possible that the radii for the second group (yellow circle) are overestimated as these three events were recorded during the early days of the seismic monitoring systems with only a few sensors and the calculated source parameters i.e. corner frequency are not very reliable.

\subsection{Manipulation and Visualization of the Source Locations}

As part of a methodology, the mXrap software (designed to serve as a platform that allows an integration of mine seismicity, with mining and geotechnical data for both geotechnical and seismological analysis (Harris and Wesseloo 2015) was used for manipulations and visualization of the source locations used for analysis of short-term hazard parameters. Firstly, the refined hypocenter locations and source parameters obtained in a previous study (Nordström et al. 2017) and the $m X$ rap routine database was updated. Secondly, spatial and temporal filtering of the data related to each event selected for analysis was performed following the approach described in details in the next section. Thirdly, plots for each of selected five hazard indicators were generated in $\mathrm{mXrap}$ (Sect. 4.1; Figs. 3, 4, 5, 6) and 
further back analysis of the indicators performances was done visually based on the generated plots.

\subsection{Back Analysis: Approach for Evaluating the Hazard Indicator Performance}

A seismic event that caused damage was called 'main' event. For this study an additional custom option was developed in $\mathrm{mXrap}$ to select a group of seismic events around the main event (before the event). The group of selected seismic events is within the area of inelastic deformation around the hypocenter location, assuming that this was the area of seismic event preparation. We considered this area to be a sphere with a radius equal to the radius of the seismic source of the main event. In tectonic and anthropogenic events a one source size distance selection corresponds to near field patterns (Parsons and Velasco 2009; Tahir et al. 2012; Grasso et al. 2018). The events that occurred within the area 30 days before the analyzed main event were included in the analysis. The behavior of the stress and deformation indicators (Table 1) were studied 5 days before the damaging event and compared with the behavior in the whole 25-day period of time (seismicity background) before these 5 days. Normally short-tern hazard is done for 3 days. During our studies the hazard indicators showed noticeable behaviors 5 days before the main event and we therefore considered that time period. The first 25 days history was considered as a "background seismicity behavior" and it was also investigated if some unusual behavior could possibly be identified (warning/alarms), related to other larger seismic events before the main studied event or without relation to any seismic event (false warning).

During discussions with LKAB personnel, it was found out that by 2013 when this study started the seismic hazard analyzing system was based on manual grouping of auto generated clusters by $\mathrm{mXrap}$ that had similarities of source parameters. The clusters were analyzed and grouped by someone at LKAB with the knowledge about the mine rock mass and geological settings. Different groups were created based on known or identified possible geological structures and significant rock mass settings. This was time consuming, subjective and involved a lot of uncertainty when grouping events into different groups. Hence, we consider the proposed approach for choosing the area for back analysis to be objective and repeatable, and independent of the experience of people that could apply it, with no previous knowledge about the geological structures, weak zones, etc. required.

After identification of short-term hazard indicators (based on literature studies, Sect. 2.2) and development of selection criteria (Sect. 3.1) the following steps were set up and followed for the back analysis.

Step 1 Definition of a source sphere with a radius equal to the source radius of the main back analyzed event using the refined source locations and parameters (Nordström et al. 2017), updated in the $m X$ rap database. The main analyzed event was used as the reference center event. The sphere contains a group of both shear and non-shear events, defined by $E_{S} / E_{P}$ ratio, for a period of one month before the main event. We considered the sphere as a region of seismic preparation and inelastic deformation during the main analyzed events.

Step 2 Spatial filtering of ore-pass-related events was done in case that there were ore passes within the source sphere. All seismic events with hypocenters within a cylinder with specific radius $(30 \mathrm{~m})$ along the ore pass were excluded. This process involves removal of a cloud of events clustered around the ore passes within the whole magnitude range. In reality the orepass size increases with time and these are not all events related to the orepasses. Because there is no standard method to differentiate ore-pass-related events from real events, this step could have, to some degree, a level of uncertainty. The plots for the selected five short-term hazard indicators were then generated for further back-analysis for all cases.

Step 3 Determination of whether the main event occurrences were blast-related (following a production blast) or not. Blasts that took place 3 days before the main event and fell within the event's sphere were considered as related to the events. The blast information was available on the hazard indicator plots generated in step 2.

Step 4 Analysis of the behavior of the five hazard indicators within 5-day period before the main events and assessment of the agreement between the 
observed and expected behavior as defined in Sect. 2.2.

Step 5 Analysis of the behavior of the five hazard indicators within 25 days before the 5-days period (Step 4) (background seismicity behavior) and identification of cases of some unusual behavior that possibly could be related to larger seismic events before the main studied event (warning) or without relation to any seismic event (false warning).

Step 6 Scoring, ranking and evaluation of the short-term hazard assessment indicators performance related to the main event and the background behavior.

Summary of the whole procedure followed during the analysis is shown on the flow chart in Fig. 2.

\subsection{Challenges with the Back Analysis}

Minimum 12 seismic events within the source sphere were considered adequate for the analysis. The threshold number of 12 was chosen as a reasonable number for which the analysis could be made. In one case $\left(M_{L}=1.2\right)$ there were less than 12 events in the source sphere and the source sphere radius was increased three times to perform the analysis. For one event the source was increased three times but a minimum acceptable number of events (12) could not be achieved. The time period before the main event was fixed for all cases at 30 days.

\section{Results}

Back analysis was performed for 14 events following the chart flow on Fig. 2. Examples of the results shown here are from Step 4 to Step 6 (Fig. 2).

\subsection{Examples from Step 4 to Step 6}

In Figs. 4, 5, 6 and 7, $a$ (indicates expected behavior before an event occurred, "warning") $b$ (indicates an event occurrence $\left(M_{L} \geq 0.8\right)$ without expected precursory behavior before, "missed event") and $c$ (indicates expected behavior with no event occurrence, "false warning").

In one case the ore-pass-related events were filtered out (Step 4). Examples of hazard indicators behavior for this event with unfiltered and filtered ore-pass-related events are shown in Figs. 4 and 5.

An example of an event that is possibly related to two blasts: production blast $22 \mathrm{~h}$ before ( $65 \mathrm{~m}$ away) and development blast $20 \mathrm{~h}$ (94 m away) is shown in Fig. 5. It should be noted that these two blasts were outside the analyzed source sphere with a radius of $48 \mathrm{~m}$.

An example of an event that is related neither to a blast or is ore-pass-related event is shown in Fig. 6.

The example of an event with ore-pass-related events (Fig. 3) shows all the events within a sphere with a source radius of $48 \mathrm{~m}$ (Fig. 3, top left. The

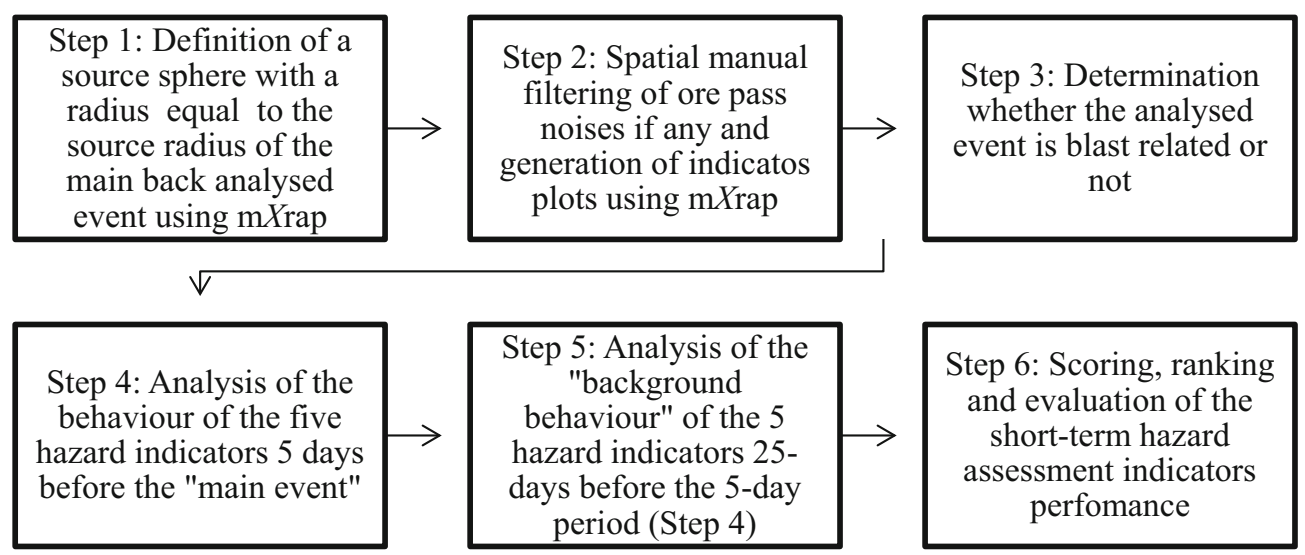

Figure 2

Back analysis flow chart (steps 1-6 defined in the text) 


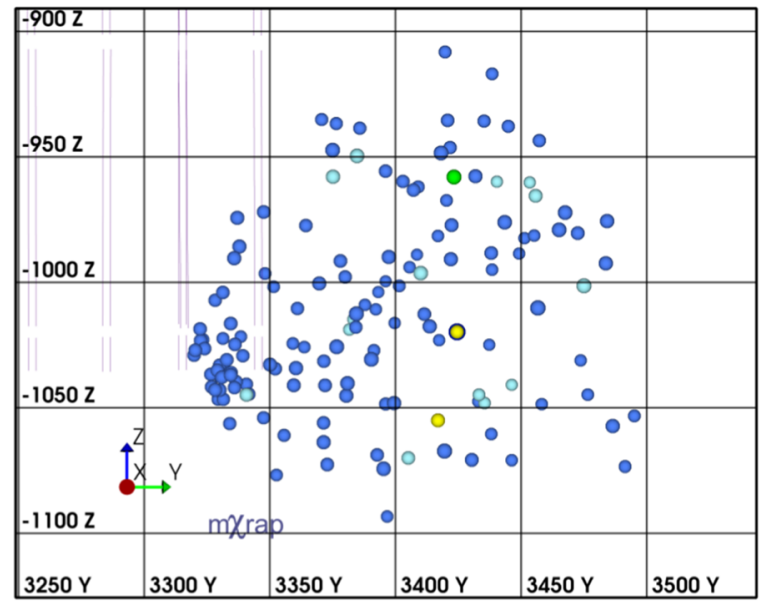

Events in the analysed sphere

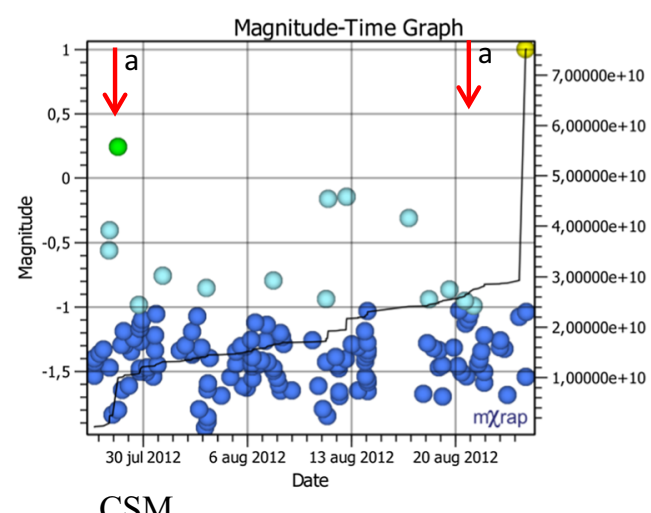

CSM

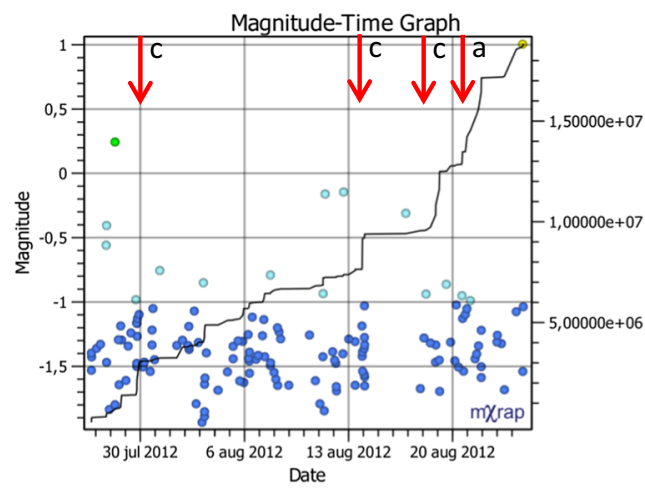

CAV

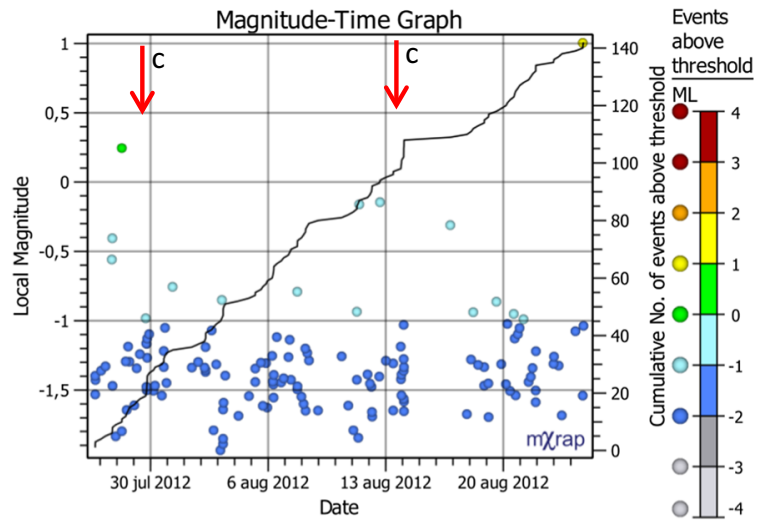

SAR

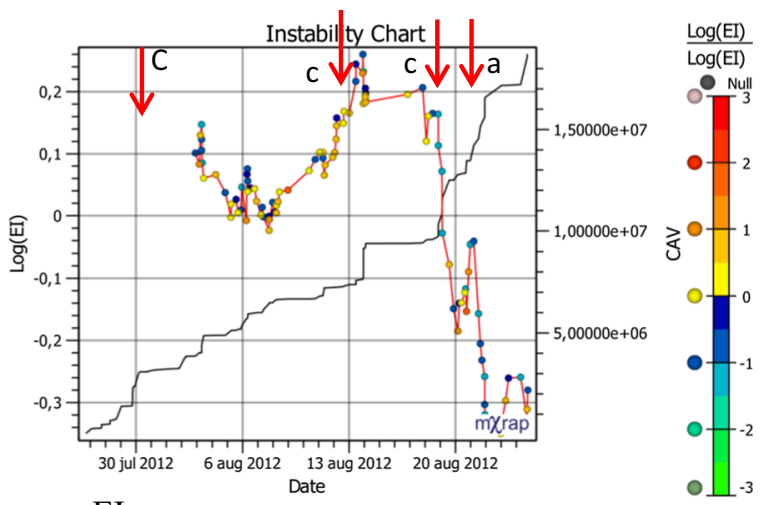

EI

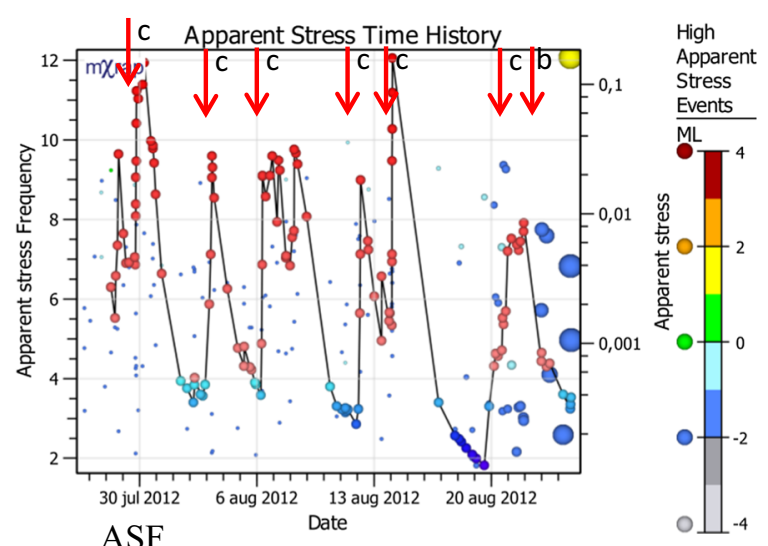

Figure 3

Examples of spatial distribution of all event 1 month before the main event and temporal indicator behaviour (SAR, CSM, EI, CAV and ASF) for an event with ore pass noises not filtered out. The main analysed event has $M_{L} 1.8$ circled in blue (top left) with a source radius of $48 \mathrm{~m}$. The ore passes are the red lines (top left). The black lines represent the cumulative values. The colored dots represent the individual seismic events with color corresponding to the scales as shown on the right of every plot (prepared in mXrap software, Harris and Wesseloo 2015) 
indicator behavior for SAR (Fig. 3, top right) and ASF (Fig. 3, bottom right) before the main analyzed event were found to be not as expected ( $b$ case). Both SAR and ASF are expected to increase. However, CSM (Fig. 3, middle left), EI (Fig. 3, middle right) and CAV (Fig. 3, bottom left) showed an expected behavior-an increase in CSM and CAV and drop in EI ( $a$ cases) before the main analyzed event. On the same Fig. 3, the background behavior for the 25-day period before 5 days analyzed for the main event showed expected behavior for several occasions but no event occurrence was observed in the sphere (false warning, case $c$ ) and many of these false warnings were recorded from ASF (Fig. 3, bottom right).

When the ore-pass-related events were manually filtered out from the sphere around the main event, some of the indicator behaviors changed as shown in Fig. 4. For example one more false warning case of (c case) was observed (Fig. 4, bottom left). The behavior of SAR, remained the same however, small change without substantial increase was observed in SAR ( $b$ case, again) and decrease in ASF (b case, again). The number of false warnings for ASF (expected behavior with no event occurring, $b$ ) decreased in the first 25 days from 6 to 4 (Fig. 4, bottom right).

An example of an event with blasts in proximity (Fig. 5) showed opposite behaviors (event but no alarms, case $b$ ) before the main analyzed event, for all indicators: SAR, CSM, EI, CAV, ASF (Fig. 5).

An event with $M_{L}>0$ in the background (25-day period before the main event) occurred around 11 June 2012, where all indicators showed expected behavior (case $b$ ) a day before. At the end of May 2012 expected behavior with no event occurrence was observed for SAR, CSM and CAV but not for EI and ASF (Fig. 5). It should be noted that this was right in the beginning of analysed period.

An example of an event with neither ore pass events nor blasts in proximity (Fig. 6) showed foreshock event with $M_{L}>0$ before the main analyzed event. All indicators showed expected behaviors (case $a$ ) before the event. Expected behavior with no event occurring (case c) for other events in the 25-day period background was also observed on all indicators with many counts of ASF (Fig. 6).

\subsection{Indicator Performance for the Main Analyzed Events}

For each back analyzed event a value of the indicator was set equal to "1" if the expected behavior (warning) was observed before the analyzed event occurrence (case $a$ ), and equal to " 0 " if there was no expected behavior (no warning) before the event occurred (case $b$ ). Each indicator was assessed to determine its performance in terms of warning $(A)$ or no warning $(B)$ using the following equations:

$$
\begin{aligned}
A_{i} & =\frac{\sum_{j} a_{i j}}{N} \times 100 \\
B_{i} & =\frac{\sum_{j} b_{i j}}{N} \times 100,
\end{aligned}
$$

where $i=1(S A R), 2(S C M), 3(E I), 4(C A V)$ or $5(A S F), j=1, \ldots, \mathrm{N}$ (14 analyzed events).

$$
\begin{aligned}
& a_{i j}=\left\{\begin{array}{l}
0-\text { no expected precursor behaviour } \\
1-\text { expected precursor behaviour }
\end{array}\right\} \\
& b_{i j}=\left\{\begin{array}{l}
1-\text { no expected precursor behaviour } \\
0-\text { expected precursor behaviour }
\end{array}\right\}
\end{aligned}
$$

$N=$ total number of analyzed events (14 events), $A_{\mathrm{i}}=$ total percentage of warnings for indicator $i$ before an event occurred, $B_{\mathrm{i}}=$ total percentage of no warnings for indicator $i$ before an event occurred.

Equations (1) and (2) were applied for each indicator $i$ for all events $N$ and the results are presented in Fig. 7.

The results showed that SAR, CSM, and CAV were equally reliable with warning in $71.4 \%$ of cases, followed by EI (in 64.3\%). ASF was the least reliable with warning only in $50 \%$ of all cases (Fig. 8).

\subsection{Indicator Behavior Before the Main Event (Background Seismicity)}

During the period of 30-5 days before the main event (background seismicity), it was observed that events with $M_{L}>0$ had prominent warnings for all five indicators (SAR, CSM, EI, CAV and ASF). We have decided to look separately into these events and evaluate the warning merits for them.

The behavior of all five indicators (SAR, CSM, EI, CAV and ASF) was also analyzed before the main 


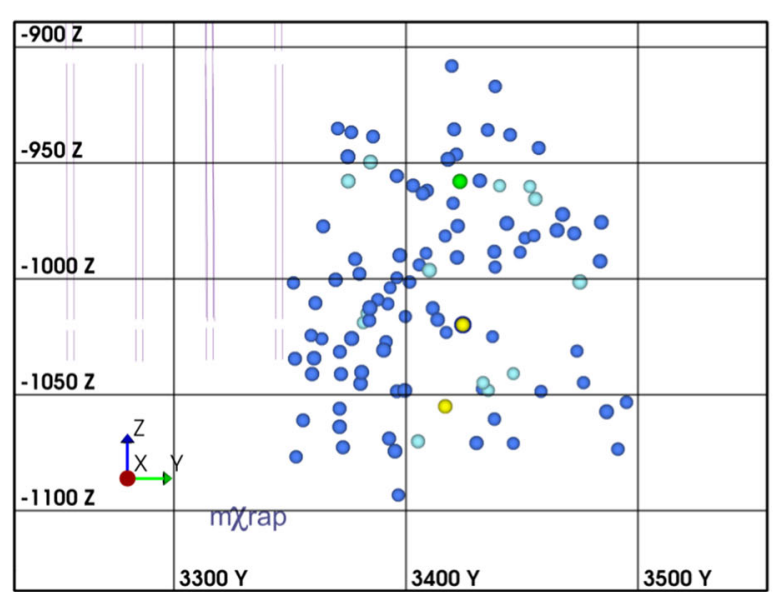

Events in the analysed sphere
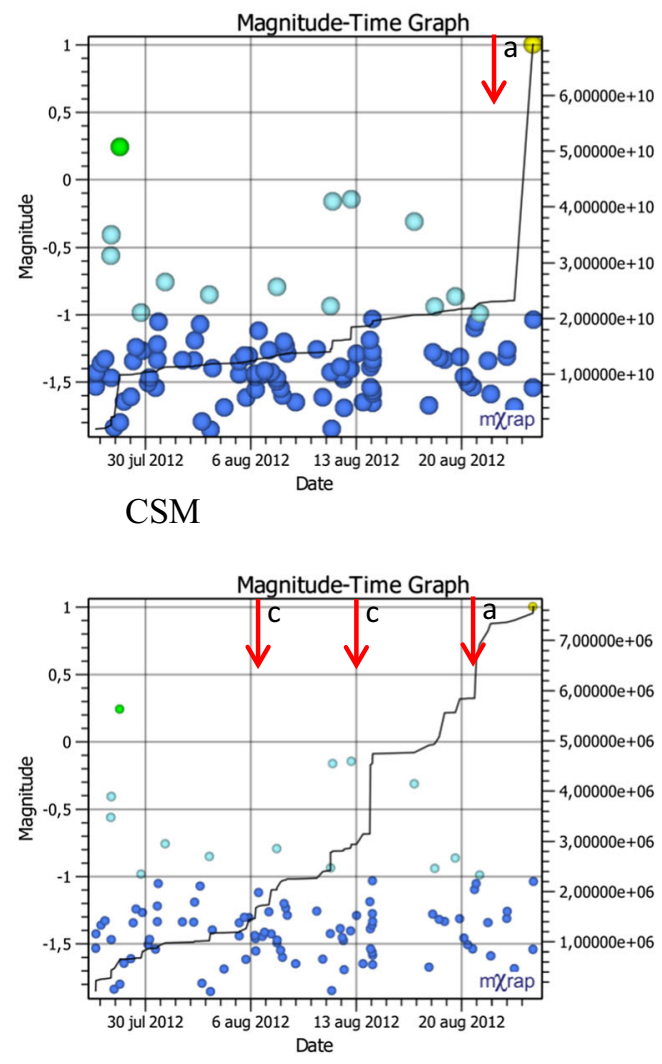

CAV
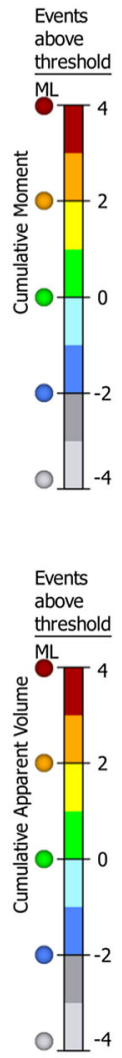
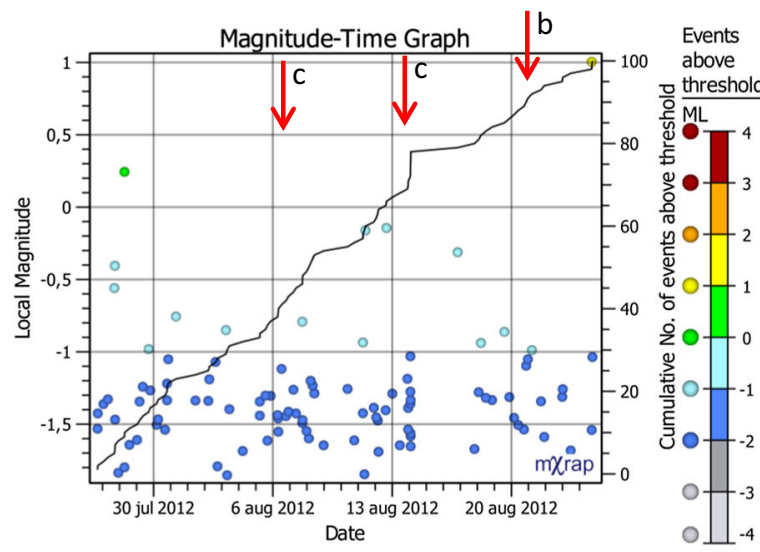

SAR

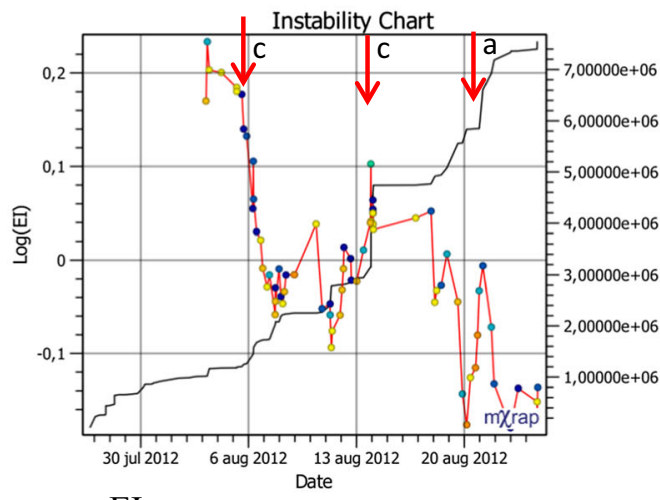

EI

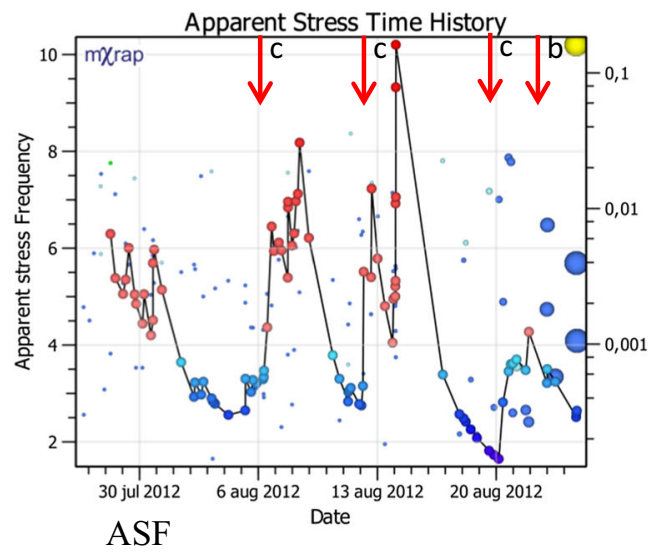

High

Apparent

Stress

Stress

Events
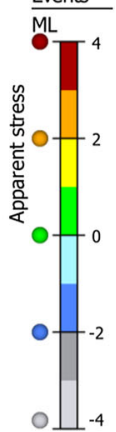

Figure 4

Examples of spatial distribution of all event 1 month before the main event and temporal indicator's behaviour (SAR, CSM, EI, CAV and ASF) for the same event above (Fig. 3) after the ore pass noises are filtered out. The main analysed event $M_{L} 1.8$ circled in blue (top left) with a source radius of $48 \mathrm{~m}$. The ore passes are the red lines (top left). The black lines represent the cumulative values. The colored dots represent the individual seismic events with color corresponding to the scales as shown on the right of every plot (prepared in $\mathrm{mXrap}$ software, Harris and Wesseloo 2015) 


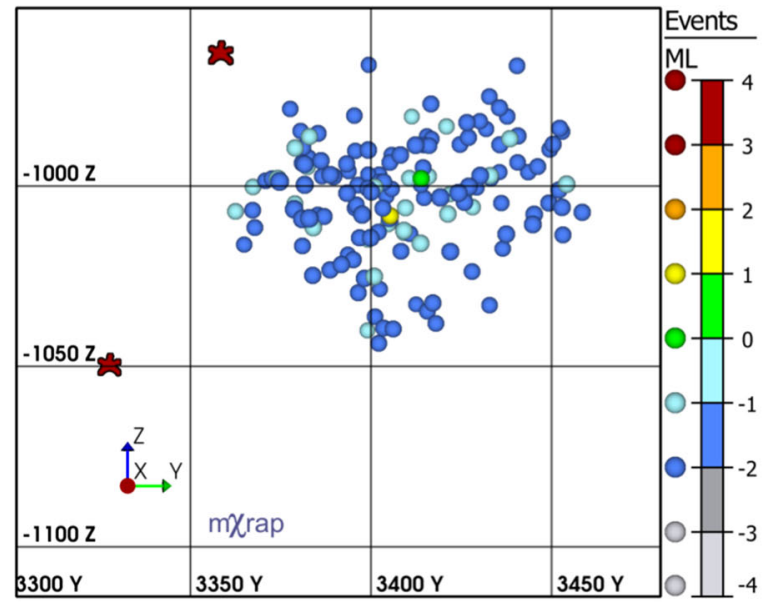

Events in the analysed sphere
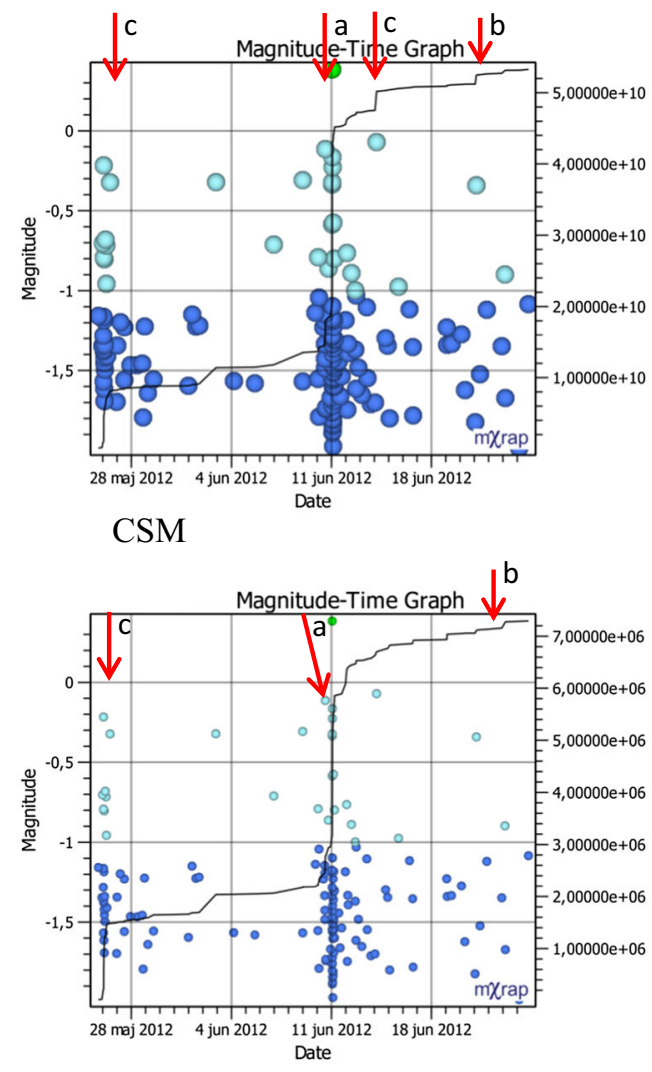

CAV

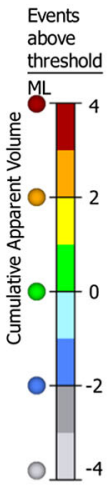

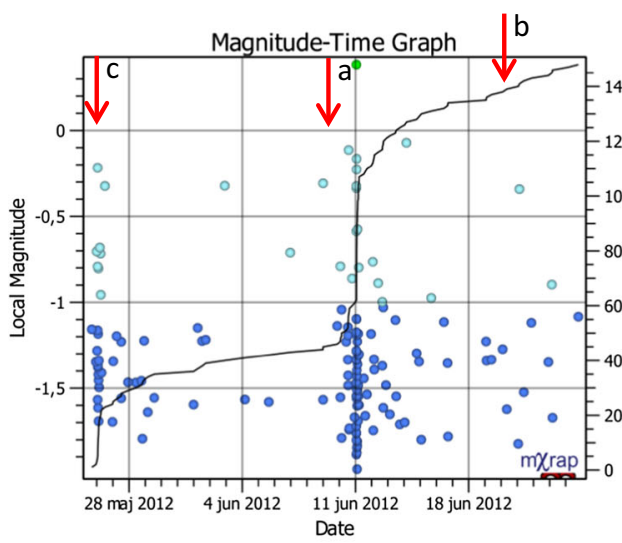

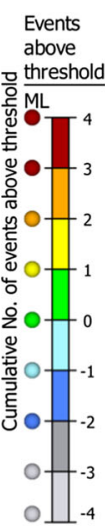

SAR

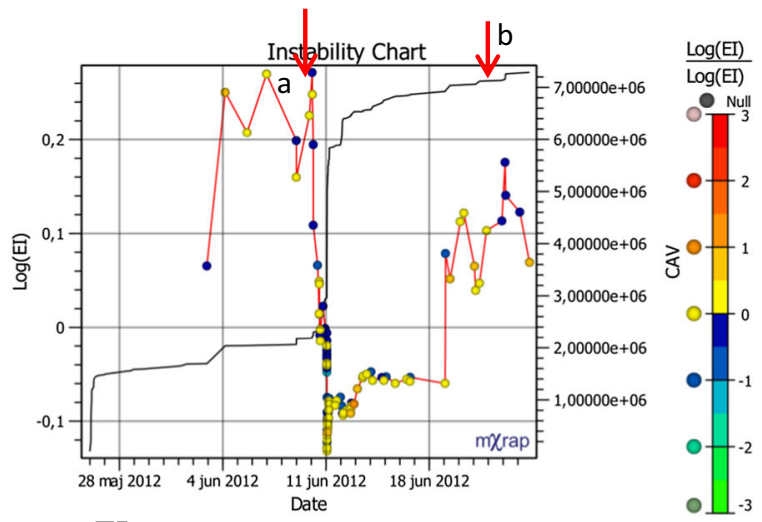

EI

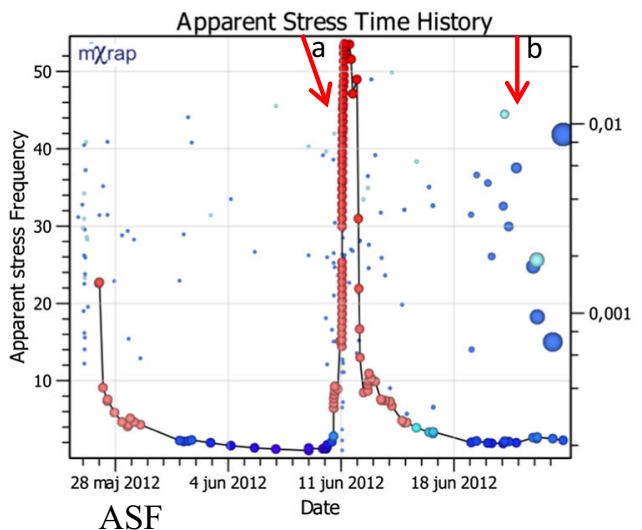

Figure 5

ASF

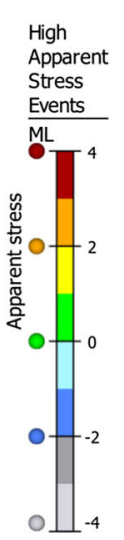

Examples of spatial distribution of all event 1 month before the main event and temporal indicator's behaviour (SAR, CSM, EI, CAV and ASF) with two blasts in a sphere's proximity: production blast $22 \mathrm{~h}$ before ( $65 \mathrm{~m}$ away) and development blast $20 \mathrm{~h}$ ( $94 \mathrm{~m}$ away). The main analysed event $M_{L}$ is 1.5 circled in blue (top left) with source radius of $48 \mathrm{~m}$. The blast location is marked with a red star. The black lines represent the cumulative values. The colored dots represent the individual seismic events with color corresponding to the scales as shown on the right of every plot (prepared in mXrap software, Harris and Wesseloo 2015) 


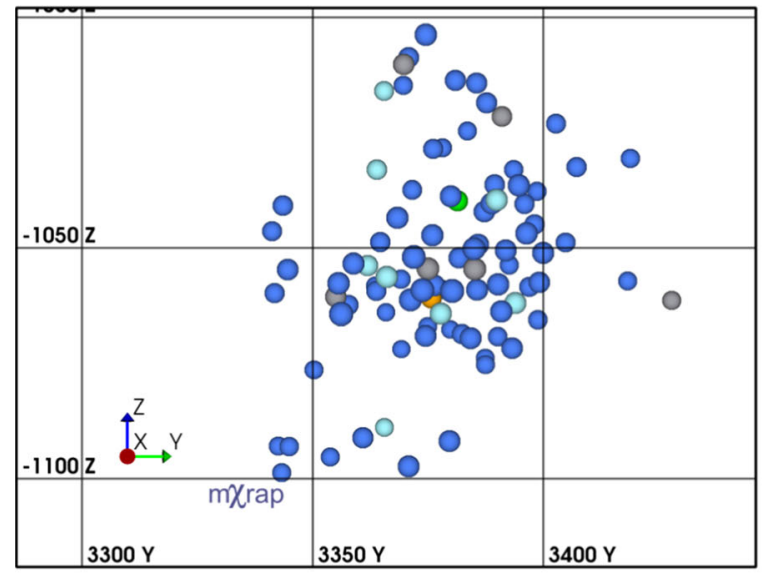

Events in the analysed sphere
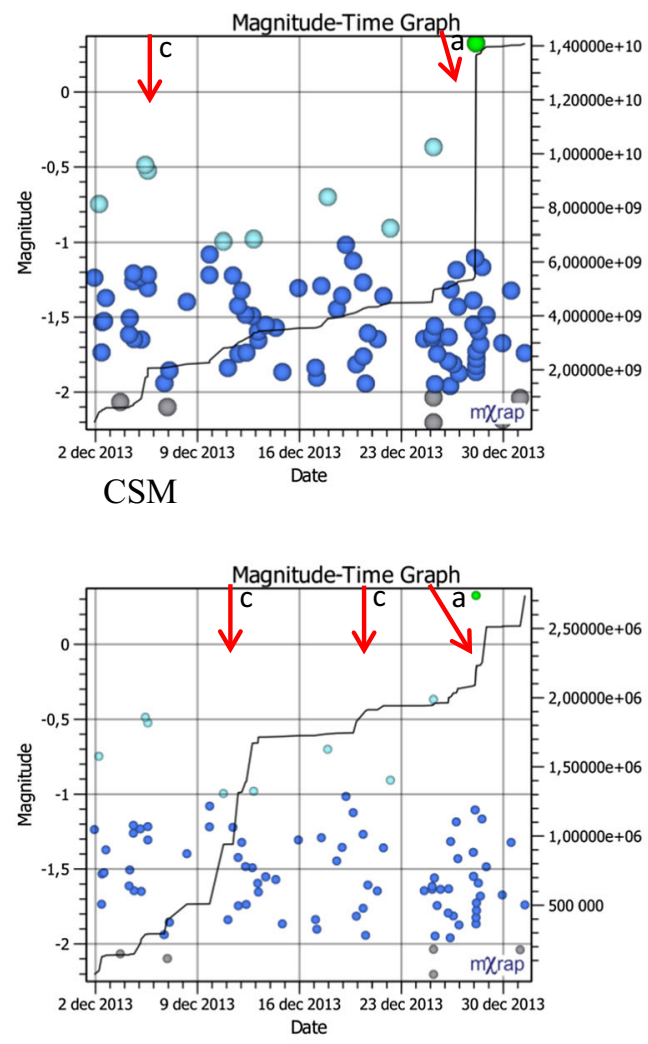

CAV
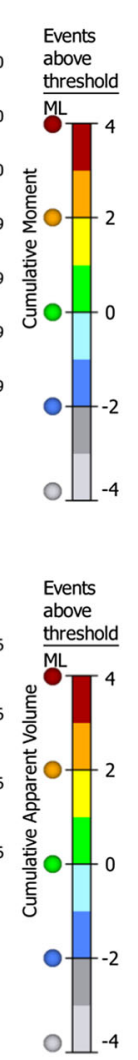
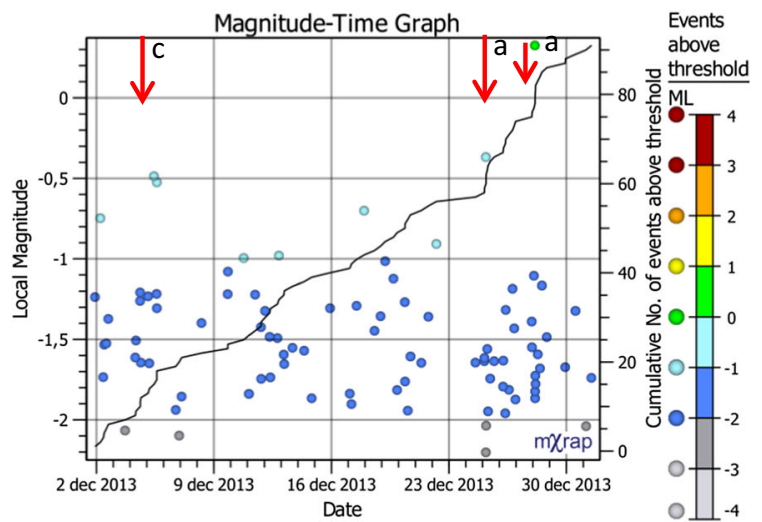

SAR
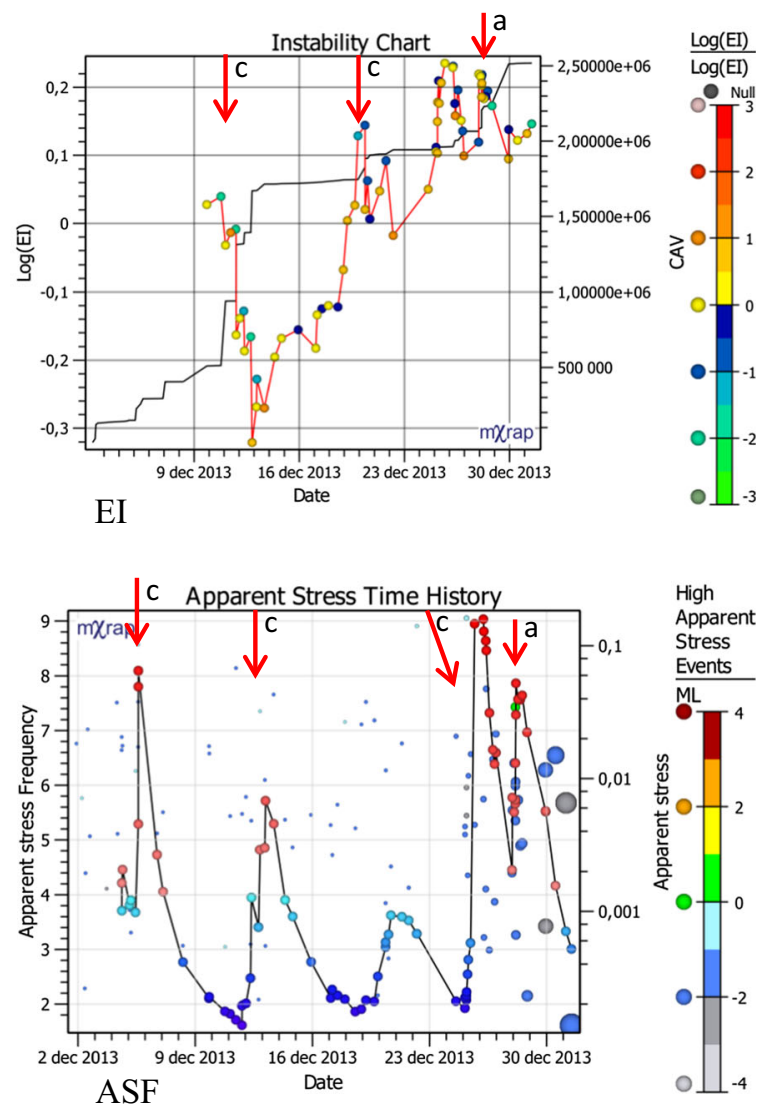

Figure 6

Examples of both spatial and temporal indicator's behaviour (SAR, CSM, EI, CAV and ASF) for an event with neither blast nor orepass noise in proximity. The main analysed event $M_{L}$ is 2.1 circled in blue (top left) with source radius of $45 \mathrm{~m}$. The black lines represent the cumulative values. The colored dots represent the seismic events with color corresponding to the scales as shown on the right of every plot (prepared in $\mathrm{mXrap}$ software, Harris and Wesseloo 2015)

event in the same sphere for a period of 25 days (background seismicity). The main aim was to see if similar type of indicator behavior that was observed for the main analyzed event could be identified for some other comparatively large events $\left(0.0 \leq M_{L}<\right.$ $0.8)$ in the sphere. Similar analysis approach used for 


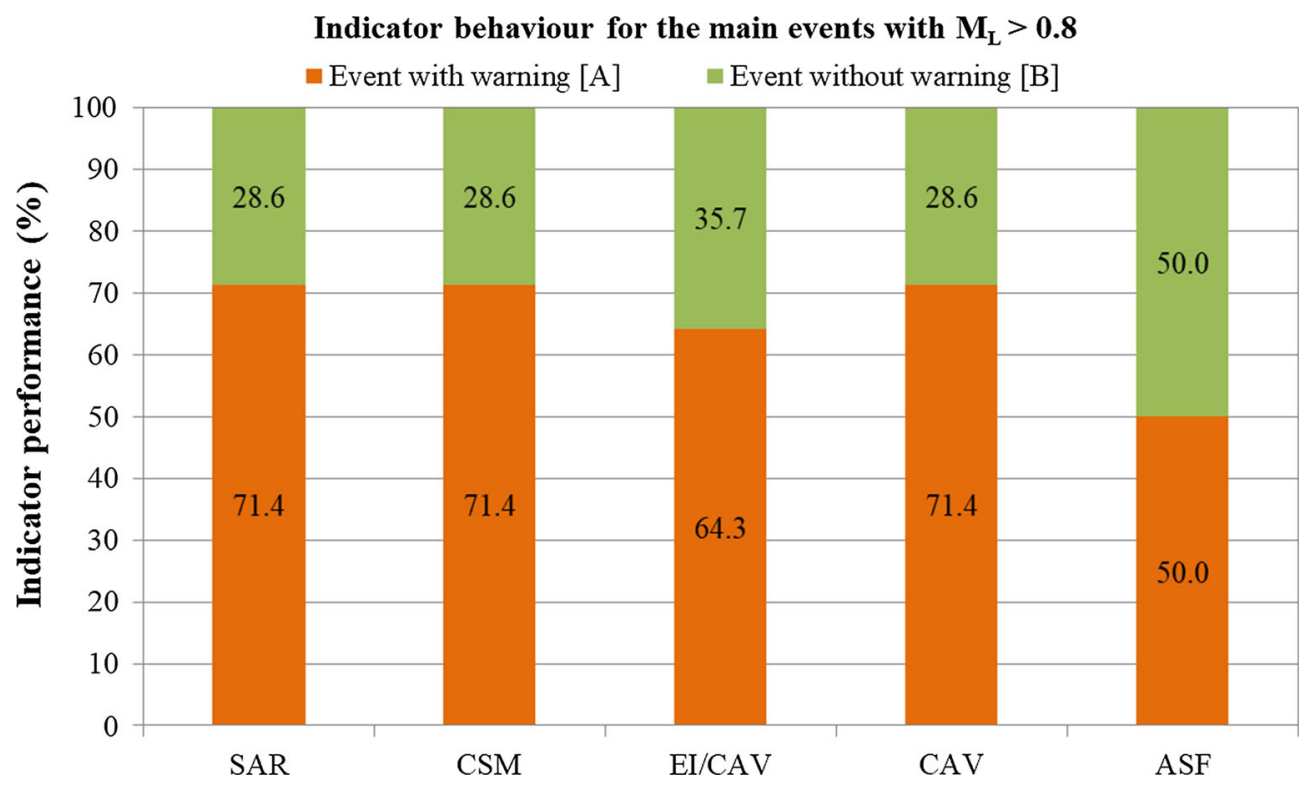

Figure 7

Performance of each indicator for the main analyzed events ( $A$ and, $B$, calculated using Eqs. (1) and (2))

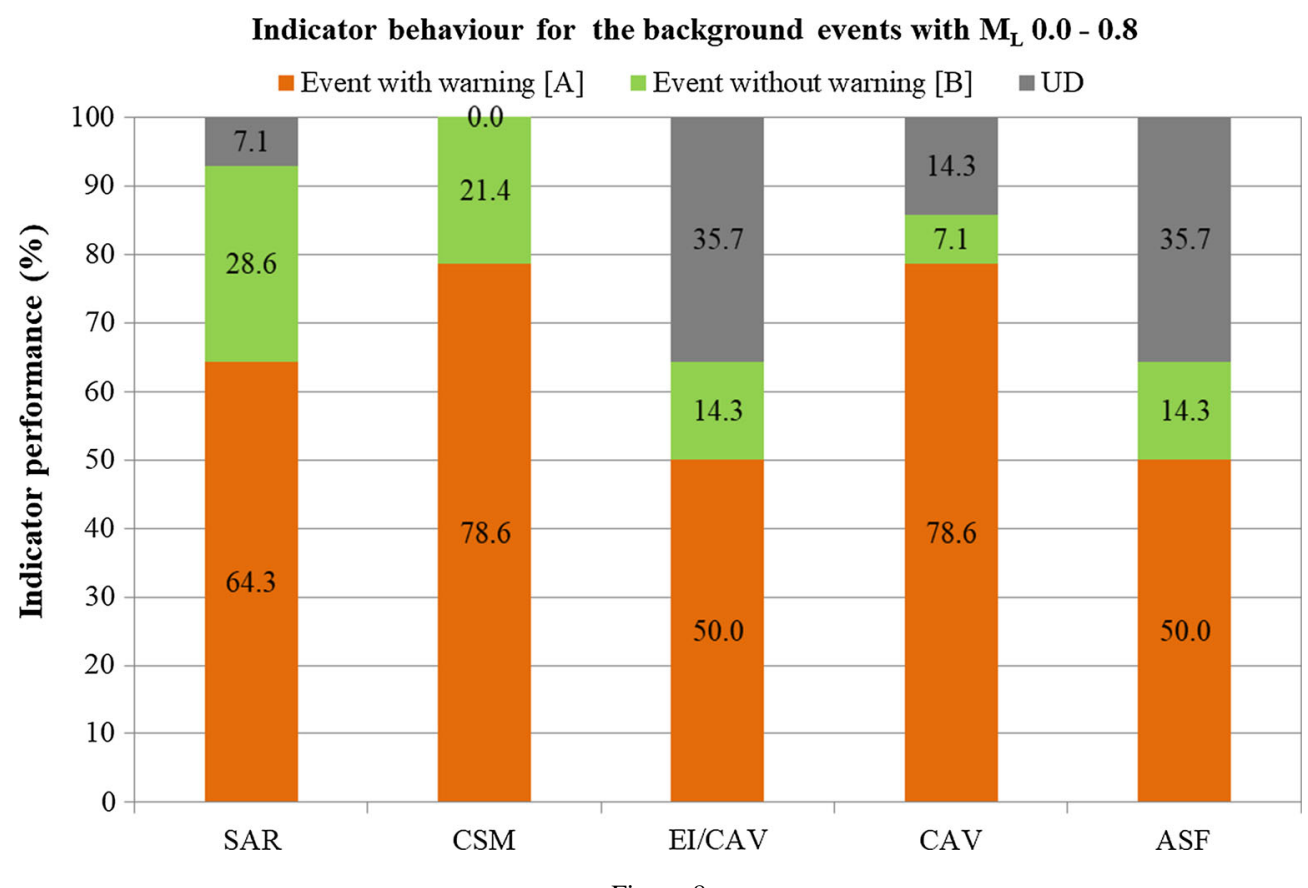

Figure 8

Performance of the indicator behavior for other events with $0.0 \leq M_{L} \leq 0.8$

the main back-analyzed events was used here except that an additional behavior was identified, when indicators were observed but there was no seismic event (case $c$, false warning). In the end three types of behavior were assessed for background events: an expected behavior before a large event occurred $(a)$, 
large event occurrence without expected behavior (b) or expected behavior with no large event occurrence $(c)$. The analyses of indicator behavior were done into two different categories: first category is when there was an event (warning or no warning was observed) and the second category was when there was no event but false warning was observed. To quantify the performance of the indicators in each category " 1 " was assigned if warning or false warning behavior was observed; otherwise, "0" was assigned.

\subsection{Indicator Behavior for Background Events with $M_{L}=0.0-0.8$ (Category 1)}

Similar analysis approach used for the main backanalyzed events was used also here. In total twentytwo such cases were observed. The equation below was used to obtain the result (summarized in Fig. 8).

$$
\begin{gathered}
X_{l}=\frac{\sum_{k} a_{l k}}{N} \times 100 \\
Y_{l}=\frac{\sum_{k} b_{l k}}{N} \times 100
\end{gathered}
$$

where $l=1(S A R), 2(S C M), 3(E I), 4(C A V)$ or $5(A S F), k=1, \ldots, \mathrm{N}$ (17 analyzed events)

$$
\begin{aligned}
& a_{l k}=\left\{\begin{array}{l}
0-\text { no expected precursor behaviour } \\
1-\text { expected precursor behaviour }
\end{array}\right\} \\
& b_{l k}=\left\{\begin{array}{l}
1-\text { no expected precorsor behaviour } \\
0-\text { expected precursor behaviour }
\end{array}\right\}
\end{aligned}
$$

$N$-total number of analyzed cases (17 events), $X_{l}$-total percentage of false warnings for indicator $i$, $Y_{l}$-total percentage of no false warnings for indicator $i, \quad Z_{l}=100-\left(X_{l}+Y_{l}\right)$-total percentage of undefined cases.

For this kind of events there is also undefined behavior (UD) as some of the events occurred at the beginning of the studied time interval and there was no information about the EI, CAV, and ASF indicators. The results showed that CSM and CAV were equally reliable with warning in $78.6 \%$ of 17 cases, followed by SAR (in 64.3\%). EI and ASF were the least reliable with warning only in $50 \%$ of all cases
(Fig. 8). These results are very similar to the results for the main events with $M_{L} \geq 0.8$.

\subsection{False and Missed Alarms for Background Events (Category 2)}

We have looked into the cases of false warnings (cases c) separately to see which of the indicators gave the highest number of false warnings and which ones the least warnings or no warnings at all. The equation below was used to obtain the result summarized in Fig. 9.

$$
U_{l}=\frac{\sum_{k} u_{l k}}{N} \times 100
$$

where $l=1(S A R), 2(S C M), 3(E I), 4(C A V)$ or $5(A S F), k=1, \ldots, \mathrm{N}$ (22 observations).

$u_{l k}=\left\{\begin{array}{l}0-\text { no false warning precursor behaviour } \\ 1-\text { false warning precursor behaviour }\end{array}\right\}$

$N=$ total number of observed cases (22 observations), $U_{l}=$ total percentage of false warnings for indicator $i$.

The results show that SAR and CAV false warnings were observed in the largest number of cases $(73.7 \%)$ followed by CSM (68.4\%). Even though these three indicators scored high for giving false warnings before occurrence of a seismic event, they also had the highest scores of no warning in case of an event. EI had the lowest false warnings but it should be noted that it has a large number of unranked events (47.4\%) followed by ASF (36.8\%) due to number of events in the sphere (Fig. 9).

\subsection{Scoring of the Combined Indicator Values for the Main Analyzed Events and the Background Events}

The sum of the warnings $(K)$ or the score of combined five indicators for each main analyzed event and background events was calculated. The sum ranges between 0 and 5 since there were five indicators. The main aim for scoring based on combined indicator values was to determine the cooperation between the five indicators for all main 


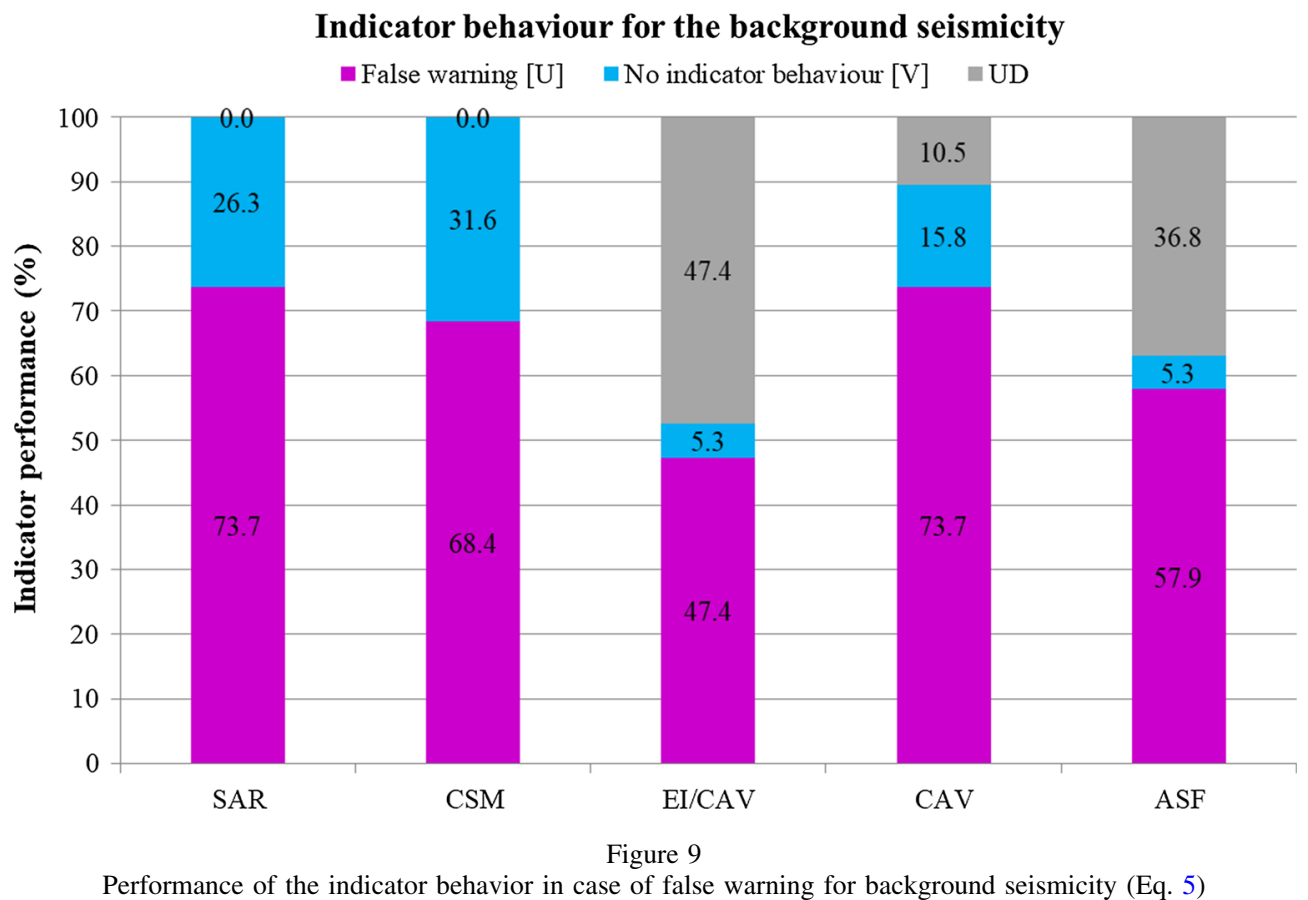

analyzed events in terms either deformation and stress changes. The score of the combined indicators $K_{j},(1,2, \ldots, 14)$ for each event was calculated using the following equation:

$$
K_{j}=\sum_{i} a_{i j}
$$

where $i=1(S A R), 2(S C M), 3(E I), 4(C A V)$ or 5 $(A S F), j=1, \ldots, N(\mathrm{~N}=14$ main analyzed events, 14 events $M_{L} 0.0-0.8$ and 19 false warning cases),

$$
a_{i j}=\left\{\begin{array}{l}
0-\text { no expected precursor behaviour } \\
1-\text { expected precursor behaviour }
\end{array}\right\} .
$$

The summary of the results is presented in Figs. 10 and 11 for the events with $M_{L} 0.0$ to 0.8 and above 0.8 (main events), and for the case of false warnings.

Out of all fourteen main events selected for back analysis, $35.7 \%$ events had a score $\mathrm{K}$ of 5 , followed by $28.6 \%$ of events with a score 4 , then $21.4 \%$ of events had a score 0 . For $7.1 \%$ of the event the score was 3 or 2 (Fig. 10).

A similar trend was observed for the events with $M_{L}$ 0.0-0.8 where the highest score 5 was observed for $28.6 \%$ of the cases followed by score 4 and 1 for
21.4\%. The lowest score 3 and 2 was observed by $14.3 \%$. No warning or only 1 indicator was observed in $21.4 \%$ of the cases for the main event and the background seismicity, correspondingly (Fig. 10).

In overall, at least four stress and/or deformation indicators were observed for at least $50 \%$ of the cases with $M_{L} 0.0-0.8$ and more than $60 \%$ of the cases with $M_{L}=0.8-2.0$ (Fig. 10).

In $26 \%$ of the cases we have 5 indicators working simultaneously and in $42 \%$ more than four indicators (Fig. 11), giving false warning for large seismic events.

\subsection{Ranking of the Indicator Behavior Performance}

The indicators were ranked to determine the ones with the highest performance of warning before an event occurred (Table 3), false warning and no warning (Table 4) for all events.

For the main analyzed events SAR, CSM and CAV were the first three with the highest warning performance before the events occurred. ASF ranked the lowest preceded by EI (Table 3). For the background seismicity events (with $M_{L}$ 0.0-0.8), CSM and CAV were the first two with the highest warning 


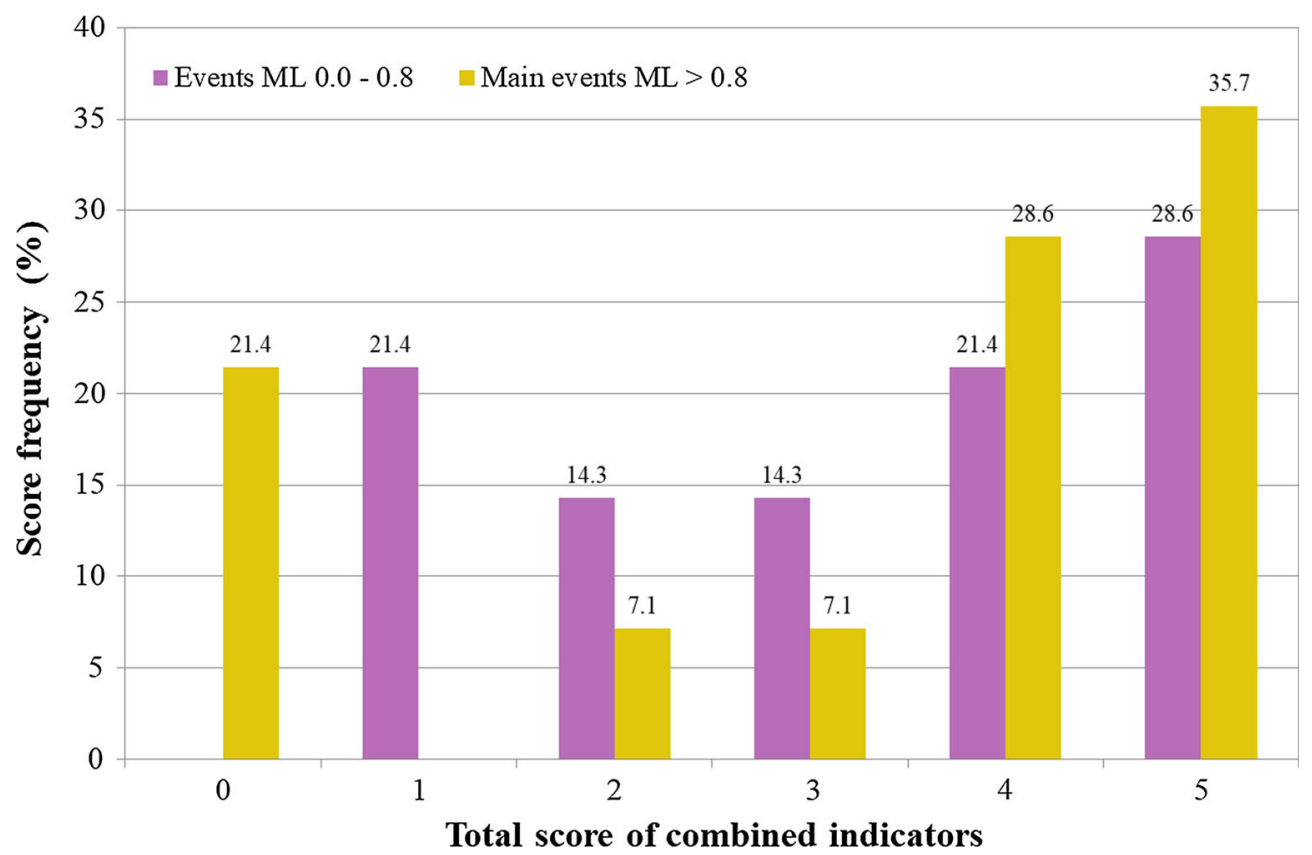

Figure 10

Combined indicator score $\mathrm{K}$ in 5-day period before the main analyzed events ( $M_{L} \geq 0.8$, purple bars) and events in background seismicity with $M_{L} 0.0-0.8$ (mustard bars)

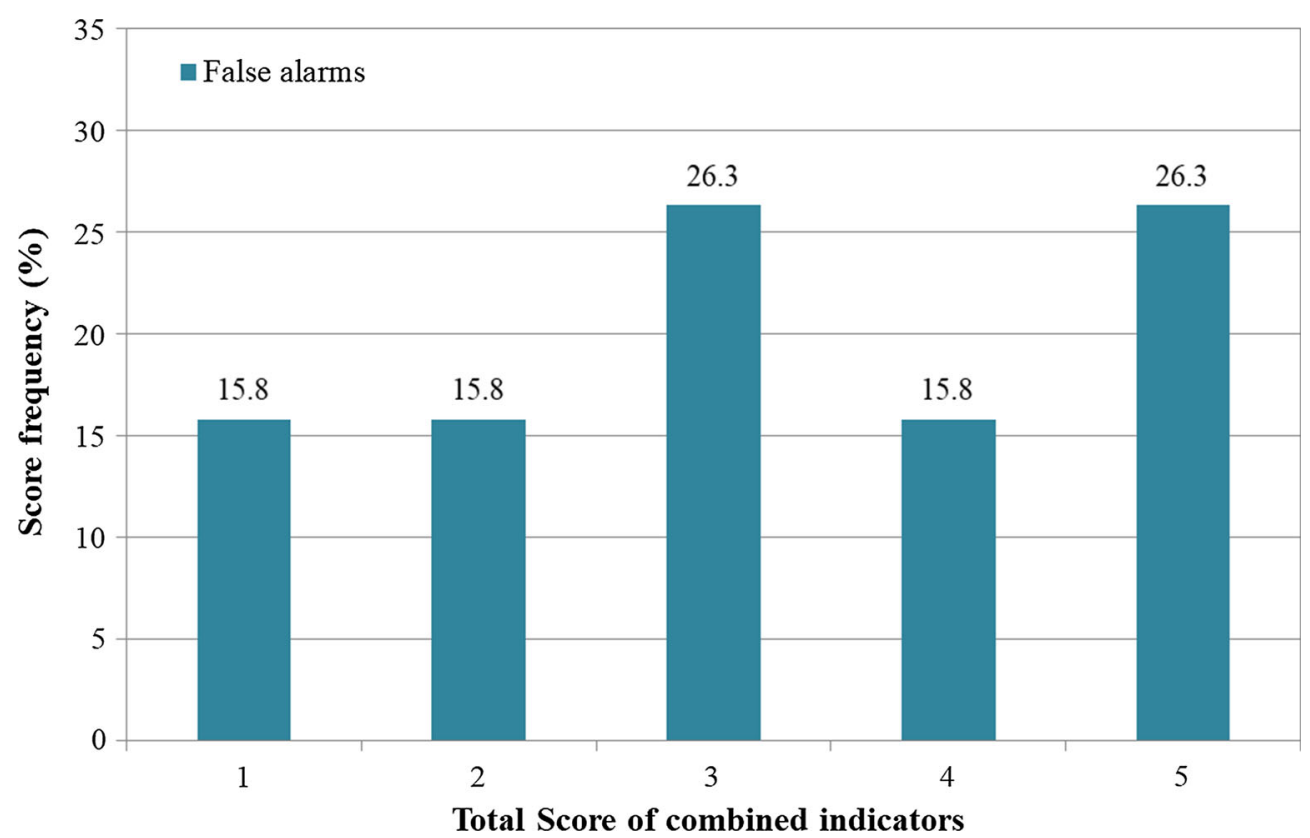

Figure 11

Combined false warning indicator score for the background seismicity 
Table 3

Ranking of indicators' warning performance

\begin{tabular}{llll}
\hline Ranking & Main event & Background events & Overall ranking \\
\hline 1 & SAR, CSM, CAV & CSM, CAV & CSM, CAV \\
2 & EI & SAR & SAR \\
3 & ASF & EI, ASF & EI \\
4 & & & ASF \\
5 & & & \\
\hline
\end{tabular}

Rank ' 1 ' is the highest and rank ' 5 ' is the lowest

Table 4

Ranking of indicators false and no warning performance for background seismicity

\begin{tabular}{ll}
\hline Ranking & $\begin{array}{l}\text { Background events } \\
\text { False warning }\end{array}$ \\
\hline 1 & SAR, CAV \\
2 & CSM \\
3 & ASF \\
4 & EI \\
\hline
\end{tabular}

performance before the events occurred followed by SAR. EI and ASF ranked the lowest (Table 3).

For the 'background events', we have also ranked the performance behavior for false indicators (Table 4).

The top three indicators (CAV, SAR, CSM) that ranked the highest with warning performance also have the highest rank of false warnings. On contrary, the indicators that were least reliable for warning (EI) showed the least false warnings (Table 4).

\section{Discussion and Conclusions}

\subsection{Methods Used for Seismic Hazard and Selected Hazard Indicators}

The seismic hazard assessment methods used in mines are adopted from natural earthquakes but with using the source parameters routinely calculated in the mines. In this study we performed back analysis for 14 damaging events and showed that there is a potential to use some of the hazard parameters/ indicators for short-term hazard assessment in
Kiirunavaara mine and possibly in other mines. The deformation indicators (CSM, SAR and CAV) ranked highest with the most reliable early hazard warning overall, and the stress indicators (ASF and EI) ranked lowest (Table 3). In overall, CSM and CAV ranked the highest positive/expected behaviour followed by SAR (Table 3), It is not surprising that CSM and CAV performed equally well due to dependency between the two parameters even though CSM is a proxy of the strain and CAV of the deformation and shear stress (see Table 1). Cumulative coseismic inelastic deformation indicates high shear stresses where a large event is likely to occur.

For tectonic seismicity forecast (e.g. Helmstetter et al. 2007; Helmstetter and Werner 2014), SAR (seismicity rate) is ranked the best "indicator" for the next event to come. Increasing the rate, increases the probability of a larger event and this is a direct consequence of the scaling between maximum observed magnitude and number of prior earthquakes defined by the Gutenberg Richter statistics (as proved by van der Elst et al. 2016 for anthropogenic seismicity). In these cases CAV and CSM were not used.

Similar kind of analysis to our analysis has been previously used to predict volcano eruption (Grasso and Zaliapin 2004). Three forerunners for predicting volcano eruptions were seismicity rate, displacement and velocity changes. A positive correlation between these fore runners and the occurrence of the volcanoes was found (Schmid et al. 2012).

Even though, the combined indicators score showed a highest score $\mathrm{K}$ of 5 in more than $50 \%$ of the cases (Fig. 10), probably using only the top three (deformation) indicators (CSM, SAR and CAV) could give better result for short-term hazard assessment given the fact that they independently performed well during the back-analysis (Fig. 8). This is so that if one indicator did not show any warnings then the other two can be used for observations. The use of the indicators with less score (ASF and EI) need to be refined to fit the used new approach during the study and enhance their early warning reliability. For example, different threshold for the ASF has to be refined to have fewer false warnings. Stress indicators need further refinement to possibly improve their performance. 


\subsection{Selection Criteria for Seismic Volume}

The selection of the volume for back analysis worked well and it was possible to carry out the analysis and to obtain results. The approach considers analysis of the indicators using parameters of the seismic events within a sphere around the hypocenter location with a radius equal to the source radius of the analyzed seismic event (area of inelastic deformation). This volume is objective and repeatable and it is not related to any geological structures, weak zones, etc. or clustering of the events. The approach is adaptable and works well with deformation indicators (CSM, SAR and CAV) even when the number of events in the sphere was small. In case of smaller number of events the stress indicators (EI and ASF) do not work very well because it was not possible to obtain a meaningful behaviour of these indicators. For example, it was possible to score the CSM, SAR, CAV parameters with limited data in a sphere $(>12$ events) but not the EI and ASF. It was observed also that when there were insufficient data in a sphere the ASF showed the opposite behaviour to the expected. From this study it can be concluded that the performance of EI and ASF is subjected to data limitation in the analysed event sphere.

It has to be stressed that the behaviour of the indicators for the smaller events $\left(M_{L} 0.0-0.8\right)$ in the background seismicity was studied for the same sphere as the main events $\left(\mathrm{M}_{\mathrm{w}} \geq 0.8\right)$. In this case the radius of these smaller events could be smaller than or didn't even fit that of the main event, but we still observed similar behaviour as for the larger event. Hence, we can make a conclusion that the volume that has to be used to do a monitoring of the indicators could be larger than the one used here for the main events. The effect of the volume on the indicator behaviour need to be studied further.

It has to be noted also that the area of seismic preparation or inelastic deformation considered for the analysis is based on Brune et al. (1979) source model. Other source models that are used in the seismological practice (Brune 1970, 1971; Madariaga 1976) could give slightly different results because of the different source radius (correspondingly volume of analysed seismic events).
In conclusions, we can say that the adopted approach for selection of the volume around the hypocentre of the seismic events to monitor the behaviour of the deformation/stress indicators could be used in future studies of short-term hazard. The actual radius of the sphere around the source radius of the event can very slightly.

\subsection{Observed Effects of Ore Passes and Blasts}

It was observed that filtering out the ore pass events changes some of the indicator's behavior. This could indicate that some of the events that are close to the ore passes may not be related to the preparation for the larger event. Manual filtering of ore passrelated event could affect the results and therefore a much more accurate separation between the ore pass-related events and other seismic events has to be used in case of seismic hazard studies. When the ore pass events were filtered out some changes were observed in the hazard indicators: SAR remained the same, one more warning with opposite behavior was observed for CSM, the number of false warnings for ASF decreased and some false warnings at different times for EI and CAV were observed (Fig. 4). Overall it was positive for the study to exclude the ore pass events to see how the indicators are affected.

We can expect that blasts can cause seismic events without any warning and this is the case that we observed here (Fig. 5). The events following the blasts should not be considered in the same way as the other events not preceded by blasts. More study should be done to confirm this. The future study should look also at the possible time intervals and distances between the blasts and the events that follow. Different kind of blasts (production or development) should be considered separately.

\subsection{New Discoveries/Observations}

The evaluation of the indicator performance carried out in this study showed that for events with $M_{L}>0.0$ there is prominent warning behaviour of certain indicators. This prompted further evaluation of the indicator performance. The results were very similar to the result for the main events $\left(M_{L} \geq 0.8\right)$. At least four stress and/or deformation indicators 
were observed for around $40 \%$ of the cases with $M_{L}$ $0.0-0.8$ and $\sim 65 \%$ of the cases with $M_{L} \geq 0.8$ (Fig. 10).

Interestingly, the top ranked three warning indicators (CSM SAR and CAV) showed promising similar behaviour for all events with $M_{L} 0.0-0.8$ (78.6\% and 64.3\%) (Fig. 8). Unfortunately, the same parameters have also the highest occurrence without seismic events (false warnings) (Fig. 9). The other two parameters-ASF and EI ranked low for warning potential but gave a lot of false warnings. In overall it can be concluded that the deformation-warning indicators used in this study (CSM, SAR, CAV) can be considered as more reliable for short-term hazard assessment for events with $M_{L}>0$ for studies in the future.

The poor performance of the stress indicators (EI and ASF) could be related to improper averaging time interval. Their behaviour changes drastically for different averaging time intervals and with the number of events within the volume. The ASF parameter is also very sensitive to the threshold level, which is mine-dependent. The results could be different with different threshold level. Further analysis and refinement should be done for these parameters to be used as short-term indicators for larger seismic events.

The study did not consider detailed analysis to further understand and determine whether the events $\left(M_{L}>0.0-0.8\right)$ were blast-related or close to ore passes. The results on Fig. 8 may change if we considered these factors. A shortcoming of the results related to the background seismicity $\left(M_{L}>0.0-0.8\right)$ is that the events were not specifically in a sphere around each one of them but in the fixed sphere around the main event.

Lastly, in the current practice of seismic hazard assessment in mines, short-term hazards are done for a period of up to 3 days. During this study, most of the indicators had expected behaviour observed up to 5 days before the larger events $\left(M_{L} \geq 0.8\right)$ occurred. The authors propose that short-term hazard assessment should be extended and assessed for a period of more than 3 days up to 5 days to ensure reliable warning systems and to study the dependence on the magnitude.

\section{Continued and Related Studies}

The current studies did not consider the amplitude and rate of change for each of the studied parameters and the ratio between the amplitude of the anomalies and the background level. Future studies should consider these two factors and determine their hazard threshold as a way forward for quantitative short-term hazard assessment. The effect of the varied volume around the seismic event that is used to calculate the indicators should be studied too.

The duration of the anomaly was not estimated here but accepted fixed at 5 days or less. This could be another parameters related to the magnitude of the future seismic event and should be estimated in the future.

More rigorous estimation of the performance of the indicators should be done using for example the error diagram (Molchan 1997, 2003; De Arcangelis et al. 2016).

\section{Acknowledgements}

Open access funding provided by Lulea University of Technology. We would like to thank HLRC for funding the main part of this project. Ruth and Sten Brands foundation provided a scholarship for one of the authors to visit the South African mines and other mining institutions to explore their methods of seismic hazards. Funding was provided also by SIP STRIM (Vinnova) foundation, project no. 2016-0269. Further we extend our gratitude to the LKAB team: Dahnér-Lindkvist Christina, Töyrä Jimmy, Mats Stålnacke, Törnman Ville, Rutanen Henrikki, Dr. Ulf B. Andersson, Helena Sturk, and Mirjana Boskovic for the numerous valuable discussions, data provision, and for sharing their knowledge about production, seismicity and geological setting of the mine. Special thanks to the ACG team: Paul Harris and Johan Wesseloo for their continual support with $\mathrm{mXrap}$ software and modification of some modules to fit our study needs. Ernest C. Lötter from the IMS team provided a lot of support with Vantage and Trace software. Also special thanks to Kevin Riemer and his group at Sibanye Gold's regional seismic monitoring center (South Africa), rock mechanics 
and engineering group at TauTona/Savuka mine and Mponeng mine (South Africa) for sharing their experience with seismic hazards assessment in South African deep mines during the visits there.

Open Access This article is distributed under the terms of the Creative Commons Attribution 4.0 International License (http:// creativecommons.org/licenses/by/4.0/), which permits unrestricted use, distribution, and reproduction in any medium, provided you give appropriate credit to the original author(s) and the source, provide a link to the Creative Commons license, and indicate if changes were made.

Publisher's Note Springer Nature remains neutral with regard to jurisdictional claims in published maps and institutional affiliations.

\section{REFERENCES}

Aki, K. (1966). Generation and propagation of $\mathrm{G}$ waves from the Niigata Earthquake of June 16, 1964. Part 2. Estimation of earthquake movement, released energy, and stress-strain drop from the $\mathrm{G}$ wave spectrum. Bulletin of the Earthquake Research Institute, 44, 73-88.

Asencio-Cortes, G., Martínez-Alvarez, F., Morales-Esteban, A., \& Reyes, J. (2016). A sensitivity study of seismicity indicators in supervised learning to improve earthquake prediction. Knowledge Based Systems, 101, 15-30.

Asencio-Cortés, G., Morales-Esteban, A., Shang, X., \& MartínezÁlvarez, F. (2018). Earthquake prediction in California using regression algorithms and cloud-based big data infrastructure. Computers \& Geosciences, 115, 198-210.

Brune, J. N. (1970). Tectonic Stress and the spectra of seismic shear waves from earthquake. Journal of Geophysical Research, 75, 4997-5009.

Brune, J. N. (1971). Correction. Journal of Geophysical Research, 76, 5002.

Brune, J. N., Archuleta, R. J., \& Hartzell, S. (1979). Far-field $\mathrm{S}$-wave spectra, corner frequencies, and pulse shapes. Journal of Geophysical Research, 84(B5), 2262-2272. https://doi.org/10. 1029/JB084iB05p02262.

de Arcangelis, L., Godano, C., Grasso, J. R., \& Lippiello, E. (2016). Statistical physics approach to earthquake occurrence and forecasting. Physics Reports, 628, 1-91.

Dineva, S., \& Boskovic, M. (2017). Evolution of seismicity at Kiruna Mine. In 8th International Conference on Deep and High Stress Mining, Perth, 28-30 March 2017 (pp. 125-140). Australian Centre for Geomechanics.

du Toit, C. (2015). New location-dependent apparent velocity model at Kiruna Mine, IMS internal report, KIR-REP-VEL201504-CDTv1.

Gibowizc, S. J., \& Kijko, A. (1994). An introduction to mining seismology (pp. 1-399). London: Academic Press.

Grasso, J. R., \& Zaliapin, I. (2004). Predictability of volcano eruption: Lessons from a basaltic effusive volcano. Geophysics
Research Letters, 31, L05602. https://doi.org/10.1029/ 2003 GL019022.

Grasso, J.-R., Karimov, A., Amorese, D., Sue, C., \& Voisin, C. (2018). Patterns of reservoir-triggered seismicity in a low-seismicity region of France. Bulletin of the Seismological Society of America, 108(5B), 2967-2982.

Harris, P. C. \& Wesseloo, J. (2015). mXrap V5, The Australian Centre for Geomechanics, Perth. http://www.mXrap.com.

Helmstetter, A., Kagan, Y. Y., \& Jackson, D. D. (2007). Highresolution time-independent grid-based forecast for $M \geq 5$ earthquakes in California. Seismological Research Letters, 78(1), 78-86.

Helmstetter, A., \& Werner, M. J. (2014). Adaptive smoothing of seismicity in time, space, and magnitude for time-dependent earthquake forecasts for California. Bulletin of the Seismological Society of America, 104(2), 809-822.

Hoffmann, G., Sewjee, R., \& van Aswegen, G. (2001). First steps in the intergration of numerical modelling and seismic monitoring. RaSIM 5, S.A Institute of Mining Metallurgy (pp. 389-395).

Hudyma, M. R. (2008). Analysis and interpretation of clusters of seismic events in mines, Doctoral thesis, University of Western Australia (pp. 1-379).

Jager, A. J., \& Ryder, J. A. (2001). A textbook on rock mechanics for tabular hard rock mines (1st ed.). Pretoria: Department of Mineral and Energy, SIMRAC.

Keilis-Borok, V. I. (2002). Earthquake prediction: State-of-the-art and emerging possibilities. Annual Review of Earth and Planetary Sciences, 30, 1-33.

Kijko, A. (1997). Keynote lecture: Seismic hazard assessment in mines. In R. P. Young (Ed.), Rockburst and seismicity in mines (pp. 247-256). Rotterdam: Balkema.

Kijko, A., \& Funk, C. W. (1994). The assessment of seismic hazards in mines. The Journal of The South African Institute of Mining and Metallurgy, 179-185.

Kossobokov, V., et al. (1999). Testing earthquake prediction algorithms: Statistically significant advance prediction of the largest earthquakes in the Circum-Pacific, 1992-1997. Physics of the Earth and Planetary Interiors, 111, 187-196.

Lachenicht, R., Wiles, T. D., \& van Aswegan, G. (2001). Integration of deterministic modelling with seismic monitoring for the assessment of rockmass response to mining: Part II Applications, 5th International Symposium of Rockburst and Seismicity in Mines (RaSIM 5).

Madariaga, R. (1976). Dynamics of an expanding circular fault. Bulletin of the Seismological Society of America, 66, 639-666.

Mendecki, A. J. (1993). Keynote address: Real time quantitative seismology in mines, Rockburst and Seismicity in Mines-RaSiM2 (pp. 287-295). Rotterdam: Balkema.

Mendecki, A. J. (1997a). Keynote lecture: Principles of monitoring seismic rockmass response to mining. 3rd International Symposium of Rockburst and Seismicity in Mines (RaSiM3) (pp. 69-80). Rotterdam: Balkema.

Mendecki, A. J. (1997b). Quantitative seismology and rock mass stability, Chapter 10. In A. J. Mendecki (Ed.), Seismic monitoring in mines (pp. 178-219). London: Chapman and Hall.

Mendecki, A. J., \& Van Aswegen, G. (2001). Seismic monitoring in mines: selected terms and definitions. In Rockburst and Seismicity in Mines-RaSiM5, South African Institute of mining and Metallurgy (pp. 563-570). 
Molchan, G. M. (1997). Earthquake prediction as a decisionmaking problem. Pure and Applied Geophysics, 149(1), 233-247.

Molchan, G. M. (2003). Earthquake prediction strategies: A theoretical analysis. In Nonlinear dynamics of the lithosphere and earthquake prediction (pp. 209-237). Berlin, Heidelberg: Springer.

Nordström, E., Dineva, S., \& Nordlund, E. (2017). Source parameters of seismic events potentially associated with damage in block 33/34 of the Kiirunavaara mine (Sweden). Acta Geophysica, 1229-1242.

Parsons, T., \& Velasco, A. A. (2009). On near-source earthquake triggering. Journal of Geophysical Research: Solid Earth, 114(B10), B10307.

Rebuli, D. B., \& van Aswegen, G. (2013). Short Term Seismic Hazard Assessment in S.A. Gold Mines, 8th International Symposium of Rockburst and Seismicity in Mines (RaSIM 8) (pp. 323-331).

Schmid, A., Grasso, J. R., Clarke, D., Ferrazzini, V., Bachèlery, P., \& Staudacher, T. (2012). Eruption forerunners from multiparamter monitoring and application for eruption time predictability (Piton de la Fournaise) (pp. 1-16).

Shebalin, P., Keilis-Borok, V., Zaliapin, I., Uyeda, S., Nagao, T., \& Tsybin, N. (2004). Advance short-term prediction of the large Tokachi-oki earthquake, September 25, 2003, M = 81 A case history. Earth, Planets and Space, 56(8), 715-724.

Spottiswode, S. M. (2004). Mine layout design and medium-term prediction of seismicity, RaSIM 6.

Spottiswode, S. M. (2004b). Intergration of seismiciuty and modelling made simple. SANIRE, 2004, 63-69.

Spottiswode, S. M. (2009). Mine seismicity: Prediction or Forecasting, S.A Institute of Mining Metallurgy (pp. 81-98).
Tahir, M., Grasso, J. R., \& Amorèse, D. (2012). The largest aftershock: How strong, how far away, how delayed? Geophysical Research Letters, 39(4), L04301.

Tiampo, K. F., \& Shcherbakov, R. (2012). Seismicity-based earthquake forecasting techniques: Ten years of progress. Tectonophysics, 522, 89-121.

van Aswegen, G. (2003a). Towards best practise for routine seismic hazard assessment in mines. S.A. Institute of Mining Metallurgy.

van Aswegen, G. (2003b). Application of quantitative seismology in South African gold minesm RaSIM 3. Rotterdam: Balkema.

van Aswegen, G. (2005). Routine seismic hazard assessment in mines. RaSIM 6, Perth (pp. 437-444).

van Aswegen, G. (2013). Short term seismic hazard assessment in mines. S.A. gold mines. RaSIM, 8, 323-331.

van Aswegen, G., \& Butler, A. G. (1993). Application of quantitative seismology in South African gold mines. Rockbursts and Seismicity in Mines, 93, 261-266.

Van der Elst, N. J., Page, M. T., Weiser, D. A., Goebel, T. H., \& Hosseini, S. M. (2016). Induced earthquake magnitudes are as large as (statistically) expected. Journal of Geophysical Research: Solid Earth, 121(6), 4575-4590.

Wiles, T. D. (1998). Correlation between local energy release density and observed bursting conditions at Creighton mine. Ontario: Mine Modelling Pty. Ltd.

Wimmer, M., \& Nordqvist, A. (2018). Present-day sublevel caving functionality uncovered-what's next. In Proceedings of '12th international symposium on rock fragmentation and blasting, Luleå, 11-13 June 2018 (pp. 469-480).

Wyss, M., \& Brune, J. (1968). Seismic moment, stress, source dimensions for earthquakes in the California-Nevada Region. Journal of Geophysical Research, 73, 4681-4698.

(Received March 1, 2019, revised September 24, 2019, accepted October 22, 2019, Published online November 6, 2019) 